\title{
The Antimicrobial Treatment of Periodontal Disease: Changing the Treatment Paradigm
}

\author{
W.J. Loesche \\ Marcus L. Ward Professor of Dentistry, University of Michigan School of Dentistry, Professor of Microbiology and Immunology, University of Michigan School of Medicine, Ann Arbor, Michigan \\ 48109, USA
}

\begin{abstract}
Over the last 100 years, methods of surgical periodontal treatment have enjoyed a history of success in improving oral health. The paradigm of care is based on the "non-specific plaque hypothesis"-that is, the overgrowth of bacterial plaques cause periodontal disease, and the suppression of this overgrowth reduces disease risk. The central feature of this approach to care is the removal of inflamed gingival tissue around the teeth to reduce periodontal pocket depth, thereby facilitating plaque removal by the dentist and by the patient at home. Over the last 30 years, with the recognition that periodontal disease(s) is caused by specific bacteria and that specific antimicrobial agents can reduce or eliminate the infection, a second paradigm has developed. This new paradigm, the "specific plaque hypothesis", focuses on reducing the specific bacteria that cause periodontal attachment loss. The contrast between the two paradigms can be succinctly stated as follows: The antimicrobial therapy reduces the cause, while the surgical therapy reduces the result of the periodontal infection. The specific plaque hypothesis has two important implications. First, with the increasing attention to evidence-based models for prevention, treatment, outcome assessment, and reimbursement of care, increasing attention and financial effort will be channeled into effective preventive and treatment methods. Second, the recent observations that periodontal infections increase the risk of specific systemic health problems, such as cardiovascular disease, argue for the prevention and elimination of these periodontal infections. This review highlights some of the evidence for the specific plaque hypothesis, and the questions that should be addressed if antimicrobial agents are to be used responsively and effectively.
\end{abstract}

Key words. Periodontal disease, antimicrobials, clinical trials, metronidazole, clinical outcomes, anaerobes, local delivery devices, compliance

\section{(I) Introduction}

$B^{a}$ th dental decay and periodontal disease are pathophysiological responses of the teeth and surrounding structures to the overgrowth of bacteria, in the form of dental plaque, on the dento-gingival surfaces. Almost all treatment and prevention techniques have used nonspecific debridement procedures as the primary means of controlling these plaque accumulations. This nonspecific approach to the management of dental infections (the Non-specific Plaque Hypothesis) has been universally applied to all individuals, even though it has been known for many years that a minority of individuals have the majority of the dental morbidity. The severity and magnitude of dental disease in these individuals imply that they are either uniquely susceptible to the bacterial overgrowth (genetic factor) or that the bacterial overgrowth contains certain uniquely odontopathic bacterial species (specific infection factor) (Loesche, 1976).

Since 1960 , beginning with the demonstration that dental decay, and periodontal disease, were transmissible bacterial infections in animal models (Fitzgerald, 1968; Keyes, 1968), there has been evidence that most forms of human dental decay and periodontal disease are diagnosable and treatable infections. This translates to the possibility that only those individuals with a clinical infection, or at risk for a clinical infection, need to be treated. This would represent a new treatment paradigm which comes at a time in which clinical dentistry is undergoing great changes due to the decline in dental decay, the aging of the population, and challenges to the traditional reimbursement schedules.

The sudden and dramatic decline in dental decay in many countries in the last half of the 20th century has resulted in large numbers of individuals retaining their teeth into old age. This, combined with the increased longevity of these individuals, is giving rise to historic levels of dentate adults in these countries. Increasing age is a major and unmodifiable risk factor for periodontal disease (Grossi et al., 1994), and thus it is likely that the 
absolute numbers of individuals with periodontally diseased teeth will increase in the immediate future. This emerging periodontal problem provides an opportunity to apply the specific infection paradigm so as to focus antimicrobial treatment upon only those individuals whose plaques are "infected" with periodontopathogens and are therefore at risk for periodontal disease. This focus becomes very relevant if recent epidemiological studies showing a relationship between periodontal disease and cardiovascular disease can be substantiated (DeStefano et al., 1993; Loesche, 1994; Mattilla et al., 1995; Beck et al., 1996; Loesche et al., 1998a). If periodontal disease is a risk factor for cardiovascular disease, then it is a modifiable risk factor, and both the patient and the physician will want to see it controlled. Because antimicrobial agents appear to be cost-effective relative to surgical procedures, intervention studies to determine whether control of periodontal disease can prevent cardiovascular disease will probably include one or more antimicrobial agents.

It is against this background that the usage of antimicrobial agents in periodontal disease will be discussed. Antimicrobial agents are not magic bullets that can be used indiscriminantly to treat any infection, let alone a polymicrobial, chronic infection such as periodontal disease. It is premature to have a "bottom line" approach to treatment, if the infrastructure behind the usage of antimicrobial agents is not understood. A series of questions relative to patient selection, choice of drug, dosage and duration of treatment, as well as the clinical endpoint(s), needs to be answered unequivocally before the dental professional becomes an infectious disease specialist. In this review, we will draw mostly upon the double-blind studies in order to answer some of these questions that will apply to the usage of systemic and the newly developed locally delivered antimicrobial agents.

\section{(II) Whom to Treat?}

Most periodontal patients do not need antimicrobial treatment. Antimicrobial therapy should be used only when the clinical situation is serious enough to warrant this treatment and there is an appropriate diagnosis of an infection. The answer, then, as to whom to treat would be those patients who have multiple sites of inflammation associated with probing depths $\geq 5 \mathrm{~mm}$, and in whom a periodontal infection can be diagnosed. These patients would most likely receive periodontal surgery and post-operative antimicrobial treatment, as judged by the responses to a questionnaire the American Academy of Periodontology sent to its membership in 1981 and in 1988 (Anonymous, 1989). In 1981, some 904 clinicians (67\% of responders) and in 1988 some 1120 clinicians $(83 \%$ of responders) reported that they use antibiotics following surgery. In 1981, the 904 clinicians reported using 454 different dosage regimens, and in 1988, the 1120 clinicians reported using 312 different regimens for agents mostly belonging to the penicillin, tetracycline, and erythromycin family of agents. These responses indicate that antibiotic usage is routine following surgery, but that there is no uniformity of opinion as to which agent and what dosage to use.

Another type of patient to treat with antimicrobials would be the refractory patient. About 10 to $20 \%$ of patients are non-responsive to debridement procedures and access surgery and are considered as refractory to treatment (Hirshfeld and Wassermann, 1978; McFall, 1982). A wide array of antimicrobial regimens is used to treat the refractory patient (Gordon et al., 1990). Open studies have shown the combination of metronidazole and amoxicillin (van Winkelhoff et al., 1992), clindamycin (Gordon et al., 1990; Walker et al., 1993), metronidazole (Loesche et al., 1984; Lundstrom et al., 1984; Gusberti et al., 1988; Winkel et al., 1997), augmentin (Magnusson et al., 1994), doxycycline (Lundstrom et al., 1984), tetracycline (Rams et al., 1984; Haffajee et al., 1995), and ornidazole (Mombelli $e t$ al., 1989) to be effective in refractory periodontitis patients. But only doxycycline has been shown to be effective in a double-blind study (McCulloch et al. 1990), and some patients who were non-responsive to the doxycycline improved when subsequently treated with metronidazole (Aitken et al., 1992).

This choice of patient-namely, those who would require surgery in their treatment-provides a new treatment outcome which can be measured, i.e., the reduced need for surgery (Loesche et al., 1991, 1992a, 1996). This outcome measures a tangible benefit to the patient, if some or all of the surgical procedures can be avoided. If antimicrobial usage is restricted to the potential surgical patient, then the unwarranted usage of systemic and locally delivered antimicrobial agents in gingivitis and in moderate forms of periodontal disease would be discouraged. Some exceptions would exist, notably the treatment of necrotizing ulcerative gingivitis and periodontitis in HIV-positive patients, where metronidazole is often the agent of choice (Winkler et al., 1989). Another would be acute necrotizing ulcerative gingivitis (ANUG), in which the effectiveness of metronidazole in anaerobic infections was discovered by Shinn in 1962, and subsequently established in a double-blind study (Duckworth et al., 1966).

Patients who probably should not be treated with systemic antimicrobials include those diagnosed with localized juvenile periodontitis (LJP). This is a surprising recommendation, since it was these patients who were successfully treated with tetracyclines in open studies (Lindhe, 1982; Mandell et al., 1986; Novak et al., 1991). But a double-blind study in LIP patients found no benefits of 
doxycycline beyond that obtained by scaling and root planing (Asikainen et al., 1990), and other studies (Saxén and Asikainen, 1993; Gunsolley et al., 1995) also concluded that LIP patients responded adequately to scaling and root planing and did not need any systemic antimicrobial agents

\section{(III) What Agent to Use?}

Clinical symptoms do not reveal which antimicrobia! agent to use, since this choice depends upon the types of bacteria that are responsible for the periodontal pathology. If one considers that the host inflammatory response is to the non-specific overgrowth of all bacterial types in the plaque, i.e., the non-specific plaque hypothesis, then one would want to use antimicrobial agents that kill as many bacterial species as possible. If one considers that the host response is to a limited number of bacterial types, i.e., the specific plaque hypothesis, then an agent that is active against the periodontopathic species is indicated.

\section{(A) The Non-SPECIFIC PLAQue hypothesis}

It is estimated that there may be over 400 distinct species that can be found in the dental plaque, and when extensive efforts were made to classify the cultivable isolates, many were found to be previously undescribed species (Moore and Holdeman-Moore, 1994). In fact, most cultivable species were present in such low proportions that it was difficult to identify any single species as being uniquely associated with periodontal disease. This type of complexity supports the Non-specific Plaque Hypothesis' position, and if this be the case, then the flora would need to be suppressed either continuously or periodically. This can be best done by a treatment philosophy that relies upon mechanical debridement for bacterial control.

When this traditional debridement approach fails, as in the patients with refractory periodontitis, antimicrobial agents are often used to kill as many bacterial types as possible. This encourages the usage of broad-spectrum agents, or the combination of agents such as amoxicillin and metronidazole (van Winkelhoff et al., 1992). Since the plaque flora would have to be suppressed either continuously or periodically, this approach could lead to the over-usage of these agents. Consider the following quote, taken from a report evaluating the ability of clindamycin to bring under control the deteriorating situation found in refractory patients: "During the year prior to entering the study, each patient had received antibiotics as part of the periodontal treatment. Tetracycline therapy ranged from one week's to one year's duration, with most patients receiving four or five administrations of $250 \mathrm{mg}$ qid for 10 to 14 days. Every patient was also treated with at least one other antibiotic including penicillin $V$, ampicillin, augmentin, erythromycin, cephalexin and metronidazole" (Gordon et al., 1990). In another report, nine refractory patients were treated with either penicillin, tetracycline, minocycline, or metronidazole (Vandekerckhove et al., 1997). In still another study, 17 different antimicrobial regimens were used by 23 clinicians in the treatment of recurrent periodontitis (Levy $e t$ al., 1993).

These reports indicate that the clinicians do not know which antimicrobial agent to use in their search for the "magic bullet" that will kill or suppress all plaque bacteria. This is because no agent can prevent or control "all" the 400 types of bacteria that can grow on tooth surfaces. This is the legacy of the non-specific plaque hypothesis, because without a targeted pathogen(s), it is very difficult to select the appropriate antimicrobial agent. But what would the scenario be if there actually were specific bacterial pathogens in periodontal disease?

\section{(B) THE SPECIFIC PLAQUE HYPOTHESIS}

In the past 25 years, there have been over 100 studies which have compared the flora of disease-associated plaques with the flora found in plaques associated with periodontal health. This interest in the bacteriology of periodontal disease was generated by the association of A. actinomycetemcomitans with LIP (Newman and Socransky, 1977; Zambon, 1985). Previously, LIP was considered a degenerative condition known as periodontosis, and a diagnosis of periodontosis often resulted in extraction of the involved teeth. But with the recognition of LJP as an infection, treatments aimed at the reduction of A. actinomycetemcomitans in the plaques resulted in the retention of teeth that formerly were considered hopeless (Lindhe, 1982; Saxén and Asikainen, 1993). Thus, a new treatment paradigm was introduced, namely, that LIP was a treatable bacterial infection.

This led investigators to inquire as to whether other forms of periodontal disease could also be associated with specific bacterial types. The older literature identified anaerobic organisms such as spirochetes and black-pigmented Bacteroides species (now classified as Porphyromonas and Prevotella species) as putative periodontal pathogens (MacDonald et al., 1962; Rosebury, 1962). The spirochetes were shown on microscopic examination of plaques samples to increase in both numbers and proportions as the clinical condition worsened (Listgarten and Helldén, 1978; Lindhe et al., 1980; Loesche and Laughon, 1982, 1985; Riviere et al., 1995). But with the identification of A actinomycetemcomitans as a putative periodontal pathogen, emphasis shifted from anaerobes to this micro-aerophilic species. Selective media were developed that allowed it to be detected even when it was greatly outnumbered by other plaque species (Slots, 1982; Mandell et al. 1987). As a result, it was implicated, on the basis of association-type studies, 


\section{TABLE 1}

Bacterial Species Suspected to be Periodontopathogens

\begin{tabular}{lll}
\hline Species & Clinical Entity & Oxygen Sensitivity \\
\hline & & \\
Porphyromonas (Bacteroides) gingivalis & AP, EOP, RP & Anaerobic \\
Bacteroides forsythus & AP, EOP, RP & Anaerobic \\
Treponema denticola & AP, EOP, RP & Anaerobic \\
Prevotella intermedia & AP, ANUG & Anaerobic \\
Fusobacterium nucleatum & AP & Anaerobic \\
Eubacteria nodatum & AP & Anaerobic \\
Selenomonas noxia & AP & Anaerobic \\
Porphyromonas (Bacteroides) gracilis & AP & Anaerobic \\
PROS Spirochete (Treponema vincentii) & AP, ANUG & Anaerobic \\
Peptostreptococcus micros & AP, RP & Anaerobic \\
Eubacterium sp. & AP & Anaerobic \\
Selenomonas sp. & AP & Anaerobic \\
Streptococcus intermedius & AP, RP & Anaerobic \\
Actinobacillus actinomycetemcomitans & UP, EOP? RP? & Micro-aerophilic \\
Wolinella (Campylobacter) recta & AP & Micro-aerophilic \\
Eikenella corrodens & AP? & Micro-aerophilic \\
\hline
\end{tabular}

AP = adult periodontitis, $E O P=$ early-onset periodontitis, ANUG = acute necrotizing ulcerative gingivitis, $\mathrm{UP}=$ localized juvenile periodontitis, $\mathrm{RP}=$ refractory periodontitis, $?=$ evidence is equivocal.

in absolute numbers and in proportions, in plaques removed from untreated patients compared with plaques in the treated patients. Porphyromonas gingivalis was significantly increased in the patients with early-onset periodontitis. Facultative species such as $\mathrm{S}$. sanguis and A. viscosus were significantly elevated in the treated patients. A. actinomycetemcomitans could not be detected, even in the LJP patients. Subsequently, we examined over 200 plaques removed from teeth scheduled for periodontal surgery and, using DNA probes, polyclonal antibodies, and cultural methods, could detect $\mathrm{A}$. actinomycetemcomitans in about 20 to $50 \%$ of the plaques (Loesche et al, 1992b). However, P. gingivalis, Bacteroides forsythus, Treponema denticola, and spirochetes were present in 80 to $100 \%$ of the plaques, indicating that these anaerobes were more prevalent and dominant relative to A actinomycetemcomitans.

Other investigators have reported that $\mathrm{A}$. actinomycetemcomitans could not be associated with periodontal disease. Moore and Holdeman-Moore (1994),

as a putative periodontal pathogen in refractory periodontitis, early-onset periodontitis, and in the rapidly deteriorating lesion (Tanner et al., 1979; Dzink et al., 1988; van Winkelhoff et al., 1989; Slots et al., 1990a; Haffajee and Socransky, 1994). Its persistence in plaque and presence within the gingival tissue were used to design antimicrobial regimens to eradicate it from both the plaque and the gingiva (Slots and Rosling, 1983; Mandell and Socransky, 1988; Goene et al., 1990; Christersson and Zambon, 1993; van Winkelhoff et al., 1992; Goodson, 1994)

These reports indicated that both A. actinomycetemcomitans and anaerobes can be associated with periodontal disease. Thus, a comparison of the relative importance of A actinomycetemcomitans and anaerobes would be a necessary starting point to decide which antimicrobial agent to use in periodontal disease.

\section{(C) Is PERIOdontal disease aN ANAEROBIC OR MICRO-AEROPHILIC INFECTION?}

This question can be answered by studies which monitor the majority of the plaque bacterial types. We reported on both the prominent cultivable flora as well as the microscopic counts of over 400 plaque samples taken from 120 patients, including periodontal patients treated successfully, and untreated patients with early-onset periodontitis, adult periodontitis, and LIP (Loesche et al., 1985). Only spirochetes were significantly elevated, both using culture methods, identified Fusobacterium nucleatum and spirochetes with periodontal disease, but not $\mathrm{A}$. actinomyctemcomitans. In a cross-sectional study involving over 1300 subjects, Grossi et al. (1994, 1995) significantly associated B. forsythus and P. gingivalis, but not A actinomycetemcomitans, with either attachment loss or alveolar bone loss. Socransky and colleagues (1998), using DNA probes, examined over 13,000 plaques removed from 185 individuals for the presence of 40 bacterial species. Only T. denticola, P. gingivalis, and B. forsythus could be statistically associated with increasing pocket depth and bleeding on probing. The same three species plus Campylobacter (Wolinella) recta, of 18 species monitored with DNA probes, were associated with periodontal disease and progressive disease in 148 adult Chinese who had never received any type of periodontal treatment (Papapanou et al., 1997)

At least 12 other groups have found anaerobic species to be more prevalent than A actinomycetemcomitans in plaques taken from diseased periodontal sites. Ashimoto et al. (1996), using a PCR technique, found the prevalence of anaerobes such as B. forsythus to increase 10.7-fold, of P. gingivalis to increase five-fold, and T. denticola to increase 3.4-fold, when plaques from diseased sites in adults were compared with plaques removed from sites of gingivitis in children. Micro-aerophilic species showed minimal changes, i.e., A actinomycetemcomitans increased 2.1 fold, C. recta showed no increase 
and Eikenella corrodens increased 1.2-fold. Lowenguth et al. (1995), using DNA probes, found that A. actinomycetemcomitans was present in $5.5 \%$ of 219 sites that were treated with a $25 \%$ tetracycline fiber, whereas F. nucleatum was present in $70.8 \%$, P. gingivalis in $43 \%$, and Prevotella intermedia in $63.5 \%$ of the sites. In a clinical trial involving azithromycin, A actinomycetemcomitans was found in six of 46 subjects, P. gingivalis was present in nine of 44 , P. intermedia in 21 of 44 , any black-pigmented anaerobes in 39 of 44 , and spirochetes in 40 of 44 subjects (Sefton et al. 1996). A. actinomycetemcomitans could be detected in $16 \%$ of 196 subgingival plaque samples removed from sites of refractory or recurrent periodontitis, whereas B. forsythus was detected in $84 \%$ of the samples, spirochetes in $83 \%$, Fusobacterium species in $68 \%$, and P. gingivalis in $63 \%$ (Listgarten et al., 1993).

Umeda et al. (1996) examined plaques removed from pockets showing clinical symptoms of pain and suppuration and found spirochetes to account for $27 \%$ of the microscopic count, and P. gingivalis and B. forsythus to account for $26 \%$ and $11 \%$, respectively, of the cultivable count. A actinomycetemcomitans accounted for only $0.3 \%$ of the cultivable count and tended to increase as a result of treatment. Kamma et al. (1994) found F. nucleatum and $P$. gingivalis to be prevalent in $90 \%$ of 73 plaques removed from sites with depths $>6 \mathrm{~mm}$ in refractory patients. A. actinomycetemcomitans was found in only two of the 10 patients and in $11 \%$ of the sites. B. forsythus was present in $53 \%$ of the sites and, together with P. gingivalis, accounted for $23.6 \%$ and $26.7 \%$ of the cultivable flora. The indirect fluorescent antibody technique is more likely than other techniques to detect $\mathrm{A}$. actinomycetemcomitans in plaque samples (Loesche et al., 1992b). Christersson et al. (1992), using an indirect fluorescent antibody technique, examined subgingival plaques taken from the mesial surfaces of all teeth in 12 patients with adult periodontitis for P. gingivalis, A. actinomycetemcomitans, B. forsythus, and P. intermedia. The three anaerobes were present in 44 to $54 \%$ of the plaques, while A. actinomycetemcomitans was found in only $11 \%$ of the plaques. Still others, while monitoring the effect of locally delivered antimicrobials upon the plaque flora, have noted that anaerobes are both more prevalent and more numerous than A actinomycetemcomitans (Goodson et al., 1991; Jones et al., 1994; Timmerman et al., 1996; Bollen et al, 1998\}.

These studies, from many laboratories involving large numbers of samples and using diverse methods, indicate that anaerobes, rather than A. actinomycetemcomitans, are more likely to be present in, or dominate, plaques associated with disease. While B. forsythus, P. gingivalis, and $T$. denticola are the most commonly found anaerobes, others, such as Peptostreptococcus micros, are also found (Table 1).

\section{(D) Diagnosis of an ANAERobic INFECTION}

These bacteriological findings indicate that most, if not all, forms of periodontal disease are anaerobic infections due to the overgrowth of a finite number of mostly Gramnegative bacteria. But how does a clinician diagnose this infection? The phase contrast microscope combined with a video camera can be used at chairside to record the architecture of the plaque microbial community, the motility of its members, and the number of white blood cells (Keyes et al., 1978). The darkfield microscope (Listgarten and Helldén, 1978) can be used to enumerate the numbers of spirochetes in plaques removed from the most diseased site in each quadrant. Because spirochetes can be found in most individuals (Loesche and Laughon, 1982), we require that each of 3 or 4 of the 4 sampled plaques have $20 \%$ or more spirochetes before we diagnose an anaerobic infection.

The BANA test, a five- to 10-minute chairside test based on the ability of the 4 plaque samples to hydrolyze the synthetic trypsin substrate, N-benzoyl-DL-arginine2-naphthylamide (BANA), can be used to diagnose an anaerobic infection (Loesche et al., 1992C, 1997). P. gingivalis, B. forsythus, and $\mathrm{T}$. denticola each possess an enzyme(s) capable of hydrolyzing BANA, whereas 55 other cultivable plaque species do not (Loesche et al. 1990). As noted previously, these BANA-positive organisms have been significantly associated with periodontal disease in both American (Grossi et al., 1994; Ashimoto et al., 1996; Socransky et al., 1998) and Chinese populations (Papapanou et al., 1997). While the BANA test does not discriminate as to which of the three species are present, this may not be necessary, since these species tend to co-exist in the same plaques (Haffajee et al., 1998; Socransky et al., 1998), and all are anaerobes. Thus, the BANA test is essentially used to diagnose an anaerobic infection

The plaque samples could be sent to reference laboratories for cultural, immunological, or DNA probe analysis (Listgarten, 1992; Rams et al., 1992; Zambon, 1997). Cultural analysis would allow for the growth of only those anaerobes that survive the transport process However, it would permit investigators to determine whether, among those that grow, the suspected periodontopathogen is resistant to an antibiotic such as doxycycline. Such testing may not be necessary for metronidazole, since all anaerobes are uniquely sensitive to this agent (Tally et al., 1978), and resistance to metronidazole in a clinical setting is extremely rare (Waiker et al., 1985; Garcia-Rodriguez et al., 1995).

\section{(E) AGEnTS active AGAinst ANAERobes}

Doxycycline, clindamycin, members of the penicillin family, and metronidazole and its analogues are active 


\begin{tabular}{|c|c|c|c|c|c|c|}
\hline Study & $\begin{array}{l}\text { Daily } \\
\text { Dosage }\end{array}$ & $\begin{array}{l}\text { Length of } \\
\text { Treatment }\end{array}$ & $\begin{array}{l}\text { Total } \\
\text { Dosage }\end{array}$ & $\begin{array}{l}\text { Dosage } \\
\text { Relative to } \\
\text { Debridement }\end{array}$ & Other TX & Outcome \\
\hline $\begin{array}{l}\text { Duckworth ef al., } 1966 \\
\text { Sterry et al., } 1985 \\
\text { Mahmood and Dolby, }\end{array}$ & $\begin{array}{l}200 \mathrm{mg} \text { tid } \\
200 \mathrm{mg} \text { tid }\end{array}$ & $\begin{array}{l}2 \text { days } \\
7 \text { days }\end{array}$ & $\begin{array}{l}1.2 \mathrm{~g} \\
4.2 \mathrm{~g}\end{array}$ & $\overline{\text { after }}$ & curettage & $\begin{array}{l}\text { - Ulcer in ANUG } \\
\text { No effect - Cross-over study }\end{array}$ \\
\hline $\begin{array}{l}1987 \\
\text { Watts et al., } 1986 \\
\text { Clark et al., } 1983 \\
\text { Loesche et al., } 1984 \\
\text { Loesche et al., } 1991 \\
\text { Loesche et al., 1992a } \\
\text { Joyston-Bechal et al. }\end{array}$ & $\begin{array}{l}200 \mathrm{mg} \text { tid } \\
200 \mathrm{mg} \text { tid } \\
250 \mathrm{mg} \text { tid } \\
250 \mathrm{mg} \text { fid } \\
250 \mathrm{mg} \text { tid } \\
250 \mathrm{mg} \text { tid }\end{array}$ & $\begin{array}{l}7 \text { days } \\
7 \text { days } \\
7 \text { days } \\
7 \text { days } \\
7 \text { days } \\
7 \text { days }\end{array}$ & $\begin{array}{l}4.2 \mathrm{~g} \\
4.2 \mathrm{~g} \\
5.25 \mathrm{~g} \\
5.25 \mathrm{~g} \\
5.25 \mathrm{~g} \\
5.25 \mathrm{~g}\end{array}$ & $\begin{array}{l}\text { after } \\
\text { none } \\
\text { after } \\
\text { at beginning } \\
\text { at beginning } \\
\text { after }\end{array}$ & $\begin{array}{l}\text { surgery } \\
- \\
- \\
- \\
-\end{array}$ & $\begin{array}{l}\text { No effect - Cross-over study } \\
\text { - Bleeding } \\
\text { im Attachment level } \\
\text { im Attachment level } \\
\text { - Need for surgery } \\
\text { - Need for surgery }\end{array}$ \\
\hline 1984 & $\begin{array}{l}200 \mathrm{mg} \text { qid } \\
\text { repeated affer } 4 \mathrm{wks}\end{array}$ & $\begin{array}{l}5 \text { days } \\
\times 2\end{array}$ & $8 \mathrm{~g}$ & after & Chx gel & - Probing depth \\
\hline $\begin{array}{l}\text { Söder et al., } 1990 \\
\text { Loesche et al., } 1996 \\
\text { Lindhe ef al., } 1983\end{array}$ & $\begin{array}{l}400 \mathrm{mg} \text { tid } \\
500 \mathrm{mg} \text { bid } \\
200 \mathrm{mg} \text { qid } \\
\text { repeated } 2 \text { times } \\
\text { at } 8 \cdot \mathrm{wk} \text { intervals }\end{array}$ & $\begin{array}{l}7 \text { days } \\
14 \text { days } \\
14 \text { days } \\
\\
\times 3\end{array}$ & $\begin{array}{l}8.5 \mathrm{~g} \\
14 \mathrm{~g}\end{array}$ & $\begin{array}{l}\text { affer } \\
\text { after } \\
\text { affer }\end{array}$ & $\begin{array}{l}- \\
- \\
-\end{array}$ & $\begin{array}{l}\text { - Probing depth } \\
\text { - Need for surgery } \\
\text { in Attachment level }\end{array}$ \\
\hline
\end{tabular}

- Decrease in measured outcome parameter.

$m$ Increase in measured outcome parameter.

against anaerobes. Other agents such as the quinolones are also active, but because of their importance in medical infections and the development of cross-resistance between members of the quinolone family (Andriole, 1998), they should not be used.

Of these agents, metronidazole would be the first choice because it is specific for anaerobes and would not affect the facultative flora which appears to be associated with health (Loesche et al., 1985; Socransky et al., 1998). Metronidazole has also been the most extensively evaluated of these agents in periodontal disease (Table 2). There are eight double-blind studies which have shown it to be clinically effective in periodontal disease (Duckworth et al., 1966; Lindhe et al., 1983; Joyston-Bechal et al., 1984; Loesche et al., 1984, 1991, 1992a, 1996; Söder et al., 1990); two double-blind studies which showed a tendency for metronidazole to be effective, but which lacked enough subjects to show statistical significance (Clark et al., 1983; Watts et al., 1986); and two double-blind studies, each using a cross-over design, which showed it to have no value as a prophylactic agent when used in conjunction with access surgery (Mahmood and Dolby, 1987) or curettage (Sterry et al., 1985).

Doxycycline has a broader spectrum of antimicrobial activity than metronidazole, being active against some micro-aerophilic organisms. Two double-blind studies (McCulloch et al, 1990; Loesche et al., 1996) have shown it to be clinically effective in adult forms of periodontal disease, but not in LJP patients (Asikainen et al., 1990). Tetracycline would not be an acceptable choice, since approximately $12 \%$ of the subgingival plaque flora are resistant to tetracycline, and of these, all the species containing the Tet $\mathrm{O}$ gene were Gram-negative anaerobic bacteria, including all Prevotella and Bacteroides isolates (Lacroix and Walker, 1995). There are few well-controlled studies that have shown its efficacy in periodontal disease. A meta-analysis of 42 studies involving the usage of tetracycline in the period from 1965 to 1988 could find no evidence of efficacy, primarily because of the absence of properly controlled studies (Hayes et al., 1992). A recent double-blind study involving patients with both LIP and early-onset periodontitis showed a short-term, i.e., three-month, benefit in pocket reduction and attachment gain in the tetracycline-treated group which disappeared after the teeth were treated by periodontal surgery (Palmer et al., 1996).

The penicillin family, which would include ampicillin, amoxicillin, and augmentin, has been shown, in 
open studies, to be effective in refractory periodontitis, either when given alone (Walker et al., 1993) or when combined with metronidazole (van Winkelhoff $e$ al., 1992). But the efficacy of these agents for serious medical infections is threatened by the emergence of beta-lactamase-positive species, so it would seem inappropriate to use these agents in periodontal disease when alternate antimicrobials are available. Several plaque species produce betalactamases (Legg and Wilson, 1990; van Winkelhoff et al., 1997), and this enzyme is detectable in gingival crevicular fluid (GCF) (Gordon and Walker, 1993), suggesting the presence of penicillin-resistant organisms. Periodontal abscesses have been reported when patients with periodontal disease were treated with penicillin for medical reasons (Helovuo et al., 1993; Topoll et al., 1990).

The combination of metronidazole and amoxicillin was chosen for some clinical studies because A. actinomycetemcomitans was sensitive to this combination of agents in vitro (Pavicic et al., 1992). This combination will eliminate A actinomycetemcomitans from plaque samples, will reduce probing depths, and will increase attachment in patients diagnosed as having LJP, refractory periodontitis, or generalized periodontitis (van Winkelhoff et al., 1992). However, this was an open study in which only before-and-after comparisons were made, and there were no controls. Given the proven ability of metronidazole, in double-blind studies, both to lower probing depths and to increase attachment levels (Lindhe et al., 1983; Joyston-Bechal et al., 1984; Söder et al., 1990; Loesche et al., 1992a; Loesche and Giordano, 1994), it is likely that most of the improvements noted could be attributed to the metronidazole. Metronidazole alone has been shown to be effective in reducing the levels of A. actinomyctemcomitans in plaques removed from LIP patients (Saxén and Asikainen, 1993). It would seem premature to recommend the additional usage of amoxicillin without evidence that the combination of amoxicillin and metronidazole is clinically superior to either metronidazole alone, or to amoxicillin alone.

An industry-formulated combination of $125 \mathrm{mg}$ metronidazole and 750,000 IU of spiramycin in a drug known as Rodogyl has been evaluated in a double-blind clinical trial (Quee et al., 1987). This formulation was based on in vitro data which showed this combination to require one-tenth the spiramycin and one-thirtieth the metronidazole to inhibit anaerobic bacteria than when they were used individually. In the double-blind study, 50 adult periodontitis patients were subjected to scaling and root planing and were given three tablets of Rodogyl or placebo per day for 14 days. Compared with the placebo group, the Rodogyl group exhibited a significant average gain of 0.67 $\mathrm{mm}$ in attachment levels and almost complete suppression of spirochetes in the plaque for up to 6 months after treatment.
Azithromycin, a macrolide with bacteriostatic activity against oral anaerobes in vitro, was shown, in a doubleblind study, to reduce probing depths significantly in those sites initially $>6 \mathrm{~mm}$, when compared with a placebo control (Sefton et al., 1996). Azithromycin is concentrated in polymorphonuclear and mononuclear cells (Calia and Oldach, 1998), and since many of these cells exit into the pocket (Skapski and Lehner, 1976), they would, after lysis, release elevated levels of this agent in the vicinity of plaque anaerobes. Azithromycin has been able to reduce secondary medical outcomes in patients with cardiovascular disease (Gupta et al., 1997). This agent was chosen because Chlamydia pneumoniae, the bacterial species most frequently associated with cardiovascular disease (Matilla et al., 1998), can live within macrophages, and thus would be exposed to the high concentrations of azithromycin found therein. But azithromycin could improve the periodontal health of the patient, so that some of the beneficial results obtained in the Gupta et al. study could reflect a periodontal effect.

Clindamycin might be a suitable choice because of its activity against anaerobes, but no double-blind studies exist to show its clinical efficacy in periodontal disease. An open study with before-and-after measurements showed it to be effective in 30 refractory patients who had been previously treated with various combinations of systemic agents (Gordon et al., 1990).

It has been suggested that a sequence of antimicrobial agents may be more effective than either agent used alone or in combination. This possibility was based on the finding that refractory patients, who did not respond to doxycycline, were more responsive to a subsequent treatment with metronidazole than were the former placebo patients when they were also treated with metronidazole (Aitken et al., 1992). In our 4th doubleblind study (Loesche et al., 1996), patients who still had $>6$ teeth in need of periodontal surgery or extraction after the first round of systemic agents were re-treated with the antimicrobial opposite that with which they had initially been treated. Both the metronidazole/doxycycline sequence patients and the doxycycline/metronidazole sequence patients responded equally well to the second treatment. This suggests that the additional improvements noted by Aitken et al. were more a function of dosage, i.e., being treated twice, than of any uniqueness associated with the sequence.

\section{(F) Safety considerations}

All medications have potential side-effects, such as the ability to evoke an allergic reaction. The clinician needs to verify, prior to treatment, that no such problem is known to exist, and to stop treatment if complaints consistent with an allergic reaction are reported by the 
patient. There are specific concerns related to each of the recommended agents.

\section{(1) Metronidazole}

\section{(a) Bacterial resistance}

Since 1958, metronidazole has been the treatment of choice for Trichomonas vaginitis and other protozoa infections. Its usage for anaerobic infections stems from the observation by Shinn (1962) of its efficacy in ANUG. Testing of plaque anaerobes for metronidazole resistance has not disclosed any pattern of increased resistance over time (Listgarten $\mathrm{et}$ al., 1993). The emergence of resistant anaerobes among medical isolates is rare (Garcia-Rodriguez et al., 1995). The exposure of reference strains and recent plaque isolates on serial passage to sub-inhibitory levels of metronidazole resulted in the development of a low level of resistance that was deemed not to be of clinical significance if metronidazole was not used repeatedly (Larsen and Fiehn, 1997). We have not observed the development of resistant black-pigmented anaerobes in our studies, but A. actinomycetemcomitans strains resistant to $25 \mu \mathrm{g} / \mathrm{mL}$ have been reported by van Winkelhoff et al (1992) in patients in whom A. actinomycetemcomitans could not be eliminated. Thus, the emergence of clinical resistance of microaerophilic species to metronidazole is a possibility. This potential concern needs to be balanced by a risk-to-benefit ratio, and this is why we have restricted our usage of metronidazole to only those patients in whom an anaerobic infection can be diagnosed.

\section{(6) Mutagenicity}

Ames et al. (1987) developed a bacterial assay to screen chemicals for mutagenicity, to serve as a surrogate for the animal studies which had been used to screen these chemicals for potential carcinogenicity. The assay involved exposing a mutated form of Salmonella typhimurium to the chemical in question, and then looking for growth of mutants. The Ames test was positive for known mutagens and was then used to determine the potential mutagenicity of previously untested chemicals. Antimicrobial agents like penicillin were lethal for the test organism, and therefore their mutagenicity could not be assessed. However, because metronidazole would not kill S. typhimurium, a facultative organism, metronidazole was found to be mutagenic in the Ames test

Subsequent studies in mice showed that extremely high dosages of metronidazole $(625 \mathrm{mg} / \mathrm{kg}$ of animal weight) could be associated with cancer in female animals (Rustia and Shubik, 1972); the comparable daily dose in a 150-pound human would be $43 \mathrm{~g}$ (Roe, 1983).

(This human would have to take 86 tablets of $500 \mathrm{mg}$ metronidazole a day for a lifetime to be compliant!) The fact that metronidazole is used primarily for treating Trichomonas vaginal infections caused the National Organization of Women to petition the FDA in 1972 to suspend the sales of metronidazole. The FDA concluded that metronidazole should remain on the market because of the absence of any adverse effects in humans, and because other animal studies using very high dosages could not duplicate the above findings (Roe, 1983). They did include a warning label on the pocket insert in each box that high dosages of metronidazole can cause tumors in certain small rodents.

There have been 32 studies seeking to find any association between metronidazole, when used to treat Trichomonas infections in pregnant women, and birth defects. Burtin et al. (1995) performed a meta-analysis on these studies and concluded that metronidazole does not appear to be associated with an increased teratogenic risk. Periodontal disease has been suggested as a possible risk factor for causing the premature birth of low-birth-weight babies (Offenbacher et al, 1996). If the women were diagnosed with a vaginal infection and treated with metronidazole, the prevalence of premature births was decreased. It is possible that some of this clinical efficacy of metronidazole in preventing pre-term births could have involved an improvement in periodontal health. The fact that metronidazole can be considered as a treatment for pregnant women should allay any concerns about the safety of this agent.

Eventually, the Ames test was used to screen presumably harmless chemicals such as various foods, and when they were found to be mutagenic, the usefulness of the Ames test as a screening assay became questionable, i.e., there were too many false-positive results (Ames, 1986; Ames et al., 1987). In fact, if the extrapolations of a positive Ames test to cancer were correct, the prevalence of environmental mutagens is so high that the human population should long ago have been wiped out by cancer.

\section{(c) Anabuse effects}

Metronidazole can combine with alcohol to cause acute nausea in some individuals. Accordingly, a label warning users not to drink alcoholic beverages is appended to the metronidazole bottle.

\section{(2) Doxycycline}

\section{(a) Bacterial resistance}

Bacterial resistance to the tetracycline family of antimicrobial agents, including doxycycline, is common among the oral flora. About 2 to $6 \%$ of the subgingival flora and 3 to $12 \%$ of the flora on the tonsils in periodontally healthy subjects, who were not taking doxycycline, were resistant to doxycycline (Fiehn and 
Westergaard, 1990). When doxycycline was given for three weeks to periodontally diseased patients, the number of doxycycline-resistant bacteria increased 10 to 20-fold in the plaque and on the tonsils, respectively. These values returned to pretreatment levels within six months. In another study (Rams et al., 1990), a threeweek course of doxycycline resulted in more than a 10fold increase in subgingival levels of medically important pathogens such as staphylococci 111 of 21 patients). Escherichia coli (one patient), Enterobacter aerogenes (two patients), and Candida albicans (two patients). These findings are of concern, since these organisms could contribute to a persistent type of refractory periodontitis that would be resistant to most antimicrobial agents (Slots et al., 1990b).

Tetracycline resistance is a major concern, because the resistance gene is located on plasmids near the insertion sites. This is conducive to the development of multiple drug resistance if the plasmid acquires other genetic information for drug resistance at this insertion site. The tetracycline molecule can be modified, as in the case of doxycycline, to inhibit certain tetracyclineresistant forms of streptococci. However, the oral streptococci still remain among the most likely species to become resistant to doxycycline (Fiehn and Westergaard, 1990; Olsvik and Tenover, 1993). But since these organisms are not periodontopathic, and the period of increased resistance is transient, no one has yet attributed any clinical concerns to this event

\section{(6) Other complications}

The tetracyclines, like many antimicrobials, can cause diarrhea, but also have certain adverse reactions that are unique to them, such as a photosensitivity to sunlight. This response is less likely to occur with doxycycline, but patients should be advised to avoid sunbathing while taking this agent. Another complication that would be of concern to women of childbearing age is the ability of tetracyclines to act indirectly with oral contraceptives in the intestinal tract, thereby decreasing their absorption and possibly leading to an unwanted pregnancy (Barnett, 1985).

\section{(3) Clindamycin}

Clindamycin is bactericidal for aerobic Gram-positive cocci and most anaerobic bacterial species (Oldach and Calia, 1998). This spectrum of activity has made it an attractive agent for use in anaerobic pelvic, abdominal, and pulmonary infections. Its main disadvantage is the high prevalence of diarrhea, i.e., from $2 \%$ to $30 \%$ (average, $8 \%$ ), that would make this an unacceptable choice, considering the availability of metronidazole and doxycycline. More ominous is the possibility that the diarrhea could become a life-threatening super-infection due to
Clostridium difficile. This anaerobe is often a normal inhabitant of the large intestine and, because of its resistance to clindamycin, is able to overgrow and cause severe colitis. The incidence of significant colitis due to clindamycin ranges from $0.1 \%$ to $10 \%$ (Oldach and Calia, 1998). One of 30 refractory periodontal patients (3\%) treated with clindamycin developed colitis (Gordon et al., 1990).

\section{(4) Local delivery devices}

\section{(a) Lower total body dosages}

The concern over the possibility of some individuals experiencing an adverse reaction to systemic agents and the easy access of the dento-gingival surfaces have encouraged the development of vehicles to release antimicrobial agents directly into the periodontal pocket. This is a very positive development from many perspectives, not the least of which is safety due to lower total body doses of the agents.

For example, the average tetracycline content of a single $25 \%$ tetracycline fiber (Actisite ${ }^{\circledR}$ ) placed in a pocket is about $8 \mathrm{mg} /$ tooth (Goodson, 1994). If 12 teeth are treated for 10 days, the total tetracycline fiber-dosage is about 96 mg. But only $25 \%$ of this dosage is released during the fiber's stay in the pocket, giving a total body dosage of 24 $\mathrm{mg}$. The comparable systemic dosage would be I gram for 14 days, or $14,000 \mathrm{mg}$, so that the use of the fibers reduces the tetracycline dosage by more than $99.5 \%$. Similar reductions in dosage would be obtained with the $25 \%$ metronidazole gel (Elyzol ${ }^{\circledR}$ ), which delivers about $3 \mathrm{mg}$ of agent per tooth. However, this regimen needs to be repeated, and since the gel is biodegradable, all of the metronidazole reaches the body (Stoltze, 1995), so that the total body dosage for the same 12 teeth would be $72 \mathrm{mg}$. But this represents a $99 \%$ reduction in whole-body dosages compared with metronidazole administered systemically, $500 \mathrm{mg}$ twice a day for one week.

It is difficult to imagine an anabuse effect from the local deposition of a $25 \%$ metronidazole gel (Ainamo et al., 1992), or from the placement of a thin film containing metronidazole in the periodontal pocket (Loesche et al., 1996), even if multiple pockets are treated simultaneously. Nor can one imagine a tetracycline-impregnated fiber (Goodson, 1994) or doxycycline- or minocycline-containing gels causing diarrhea (Graca et al., 1997; Polson et al., 1997b). Moreover, an agent like chlorhexidine, which is too toxic to be taken systemically, can now be incorporated into a thin film which is deposited in a pocket (Soskolne et al., 1997). Thus, when high concentrations of an agent are incorporated into a vehicle that delivers the agent directly to the periodontal pocket, many of the side-effects associated with whole-body dosing, as would occur with systemic agents, should be avoided. 
TABLE 3

Double-blind Studies of Systemic Antibiotics in Periodontal Disease

\begin{tabular}{|c|c|c|c|c|c|c|}
\hline Agent & Study & $\begin{array}{l}\text { Daily } \\
\text { Dosage }\end{array}$ & $\begin{array}{l}\text { Length of } \\
\text { Treatment }\end{array}$ & $\begin{array}{l}\text { Total } \\
\text { Dosage }\end{array}$ & $\begin{array}{l}\text { Dosage Relative } \\
\text { to Debridement }\end{array}$ & Outcome \\
\hline \multirow[t]{3}{*}{ Doxycycline } & McCulloch ef al., 1990 & $100 \mathrm{mg}$ & 21 days & $2.2 \mathrm{~g}$ & After & - Recurrence \\
\hline & Asikainen et al., 1990 & $100 \mathrm{mg}$ & 14 days & $1.4 \mathrm{~g}$ & After & UP - no effect \\
\hline & Loesche ef al., 1996 & $100 \mathrm{mg}$ & 14 days & $1.4 \mathrm{~g}$ & After & - Need for surgery \\
\hline \multirow[t]{2}{*}{ Tetracycline } & Rams et al., 1984 & $250 \mathrm{mg}$ qid & 14 days & $14 \mathrm{~g}$ & After & \\
\hline & Palmer ef al., 1996 & $250 \mathrm{mg}$ qid & 14 days & $14 \mathrm{~g}$ & After & $\begin{array}{l}\text { in Attachment level } \\
\text { - Need for surgery }\end{array}$ \\
\hline \multirow{5}{*}{$\begin{array}{l}\text { Rodogyl } \\
\text { metronidazole } \\
\text { spiramycin } \\
\text { Azithromycin } \\
\text { Spiramycin } \\
\text { Combination } \\
\text { metronidazole } \\
\text { amoxicillin }\end{array}$} & $\begin{array}{l}\text { Al-Joburi a et al., } 1989 \\
\text { Quee et al. } 1987\end{array}$ & $250 \mathrm{mg}$ qid & $\begin{array}{l}14 \text { days } \\
14 \text { days }\end{array}$ & $14 \mathrm{~g}$ & $\begin{array}{l}\text { After } \\
\text { During }\end{array}$ & $\begin{array}{l}\text { No effect } \\
\mathrm{m} \text { Attachment level }\end{array}$ \\
\hline & & $\begin{array}{l}750 \mathrm{mg} \\
4,500,000 \mathrm{IU}\end{array}$ & & $\begin{array}{l}10.5 \mathrm{~g} \\
63 \times 10^{6} \mathrm{IU}\end{array}$ & & \\
\hline & Sefton et al., 1996 & $500 \mathrm{mg}$ & 3 days & $1.5 \mathrm{~g}$ & After & - Probing depth \\
\hline & $\begin{array}{l}\text { Al-Joburia et al., } 1989 \\
\text { Lopez \& Gamonal, } 1998\end{array}$ & $3,000,000 \mathrm{IU}$ & $\begin{array}{l}14 \text { days } \\
7 \text { days }\end{array}$ & $42 \times 10^{6} \mathrm{IU}$ & $\begin{array}{l}\text { After } \\
\text { No debridement }\end{array}$ & No effect \\
\hline & & $\begin{array}{l}250 \mathrm{mg} \text { tid } \\
500 \mathrm{mg} \text { tid }\end{array}$ & & $\begin{array}{l}5.25 \mathrm{~g} \\
10.5 \mathrm{~g} \\
\end{array}$ & & $\begin{array}{l}m \text { Attachment level } \\
\text { - Probing depth }\end{array}$ \\
\hline
\end{tabular}

- Significant decrease in measured parameter.

m Significant increase in measured parameter.

a Same study.

\section{(b) Bacterial resistance}

The concerns related to bacterial resistance are reduced with the local delivery vehicles, because, as a result of dilution effects, there would be almost no exposure of the intestinal flora to an agent such as tetracycline and doxycycline. However, this does not mean that the emergence of resistant organisms will not occur in the oral cavity, since some members of the oral flora will be exposed to lower concentrations of the agent in the area away from the treatment site. In one study (Larsen, 1991), the level of doxycycline-resistant bacteria was $1 \%$ in the plaque, on the tongue, and on the tonsils prior to treatment. After treatment with locally delivered doxycycline, the percentages of resistant bacteria increased to $22 \%$ and $35 \%$, respectively, on the tongue and tonsils, and then declined to pretreatment levels by week 13. This transient increase was due primarily to resistant Gram-positive cocci and was without clinical significance.

\section{(IV) What Dosage to Use?}

\section{(A) Systemic Agents}

Only a few dosage schedules are approved by the FDA. However, the creativity of the dental community in devising dosages is not to be underestimated, judging from the responses to the American Academy of
Periodontology questionnaire cited earlier, where over 300 different antibiotic regimens were used following periodontal surgery (Anonymous, 1989). Even among the research investigations, it is difficult to compare between studies because of the different dosages used. If we restrict ourselves to the 12 double-blind studies involving metronidazole, most of the factors which confound comparisons between investigations become evident (Table 2).

\section{(1) Metronidazole}

The dosages of metronidazole ranged from $1.2 \mathrm{~g}$ (Duckworth et al., 1966) to $33.6 \mathrm{~g}$ (Lindhe et al., 1983), and the length of treatment varied from 2 days to 42 days. In most studies, the metronidazole was combined with mechanical debridement, but in one study there was no debridement (Watts et al., 1986). Sometimes the taking of the metronidazole occurred at the beginning of debridement and other times after debridement had been completed. There would be fewer bacteria in the pocket in the latter situation, and this could improve the outcome because of a lower microbe-to-agent ratio (Loesche and Giordano, 1994) (Table 4). In two studies, the subjects were re-treated with metronidazole, thereby increasing the overall dosage (Lindhe et al., 1983; Joyston-Bechal et al., 1984). In one study, a chlorhexidine gel was combined with the metronidazole (Joyston-Bechal et al., 1984).

These variables make comparisons between and 
among studies difficult, but despite this, all but two showed a beneficial effect of metronidazole on the measured clinical outcomes. One failure involving a crossover design showed no benefit of metronidazole when used following surgery (Mahmood and Dolby, 1987), and since this prophylactic indication is not of value for any antimicrobial agent (Pack and Haber, 1983; Tseng et al., 1993), this outcome was to be expected. The other failure also involved a cross-over design in which both groups received metronidazole separated by a 10 -week interval (Sterry et al., 1985). Since the effect of metronidazole can last many months (Loesche et al., 1991, 1992a), it is possible that, in both studies, the wash-out period between the different treatments was so short that all participants had benefited from the metronidazole.

The multiple dosage regimens make difficult the transference of the results to clinical practice. But a pattern is obvious: Metronidazole is best given for one week after debridement of the tooth surfaces. The total dosages should be at least $5.25 \mathrm{~g}$, i.e., $250 \mathrm{mg}$ three times a day for one week, but as will be discussed subsequently, a twice-a-day (bid) regimen will improve compliance.

\section{(2) Other agents}

The dosages of doxycycline and tetracycline have been consistent between and among studies (Table 3). A twoweek treatment of doxycycline was without effect in LIP patients (Asikainen et al. 1990) but was effective in a study involving adults who needed periodontal surgery and were diagnosed with an anaerobic infection (Loesche et al., 1996). A three-week treatment was associated with a significant improvement in refractory patients (McCulloch et al., 1990). The results with tetracycline were equivocal.

Rodogy ${ }^{\circledR}$, the spiramycin-metronidazole combination tablet, was given as 3 tablets twice daily for two weeks in adult patients (Quee et al., 1987). Even though there was only a 125-mg quantity of metronidazole in each tablet, the total dosage of metronidazole in this regimen was 10.5 $\mathrm{g}$. which was higher than the dosages of metronidazole used in most of the double-blind studies involving only metronidazole (Table 2).

Azithromycin has a long half-life and good tissue penetration, so that after a dosage of $500 \mathrm{mg}$ taken once a day for three days, antimicrobial levels of the agent can be found in most tissues for 7 to 10 days (Sefton et al., 1996). This dosage schedule is by far the most convenient regimen that has been evaluated in double-blind studies and should be associated with good patient compliance (see "Compliance").

\section{(3) Dosage guidelines for systemic antimicrobials in periodontal disease}

If we note the dosages that were effective in the doubleblind studies (Tables 2, 3), as well as the general princi- ples of antimicrobial therapy, certain guidelines can be formulated in regard to dosages to be used for systemic antimicrobial agents in periodontal disease:

(1) Follow the dosage regimens found in the package insert. They are designed to provide a dosage of the agent in all body compartments, and the recommended time between doses has been empirically determined to provide a 24 -hour bactericidal/static level of the agent in the tissues.

(2) Because the periodontal pocket is extravascular, the highest possible dose should be used. Take into account the body weight of the patient. Heavier patients need higher dosages. We use $500 \mathrm{mg}$ metronidazole bid for patients weighing between 100 and 200 pounds. We increase the dosage by $250 \mathrm{mg}$ for each 50 pounds over 200 pounds, and decrease it by $250 \mathrm{mg}$ for each 50 pounds under 100 pounds.

(3) Choose a dosage schedule that improves patient compliance. A regimen in which metronidazole is taken twice a day would be better than a regimen in which it is taken three times a day. Doxycycline, and especially azithromycin, have dosage schedules that would promote patient compliance.

(4) Treatment should be as short as possible. There is little need to treat beyond two weeks unless there is evidence of improvement that is short of disease resolution. Most studies with metronidazole have lasted one week. Studies with doxycycline have lasted two weeks or more. Azithromycin is of interest because treatment lasted only three days.

(5) Monitor the efficacy of treatment. If an effect is not apparent by one week, the agent is probably not going to work.

\section{(B) LOCAL DELIVERY DEVICES}

\section{(1) Dosages}

Local delivery devices make moot a consideration of dosages, since each device brings to the periodontal pocket drug levels that are 10 - to 100 -fold more than the levels, i.e., from 2 to $10 \mu \mathrm{g} / \mathrm{mL} \mathrm{GCF}$, that can be delivered by the systemic route. For example, with the tetracycline fibers, GCF levels of tetracycline up to $1500 \mu \mathrm{g} / \mathrm{mL}$ can be achieved over a 10-day period (Tonetti $\ell$ al., 1990). These dosages make tetracycline, which is ineffective via the systemic route (Hayes et al., 1992), probably because of its poor activity against anaerobes, now capable of suppressing plaque anaerobes (Goodson et al., 1991; Maiden et al., 1991; Lowenguth et al., 1995). The 25\% metronidazole gel that is syringed into the pocket provides up to $450 \mu \mathrm{g} / \mathrm{mL}$ GCF of metronidazole (Stoltze, 1995), and the chip that contains $2.5 \mathrm{mg}$ of chlorhexidine can sustain levels of over $100 \mathrm{ppm}$ in the GCF for at least 7 days (Soskolne et al., 1997). 
These are extraordinarily high dosages, and the question becomes, how long can these devices actually maintain these levels in the pockets? Studies with the $25 \%$ tetracycline fiber (Goodson, 1994) and a biodegradable chlorhexidine film or chip (Soskolne, 1997) indicated that a seven- to 10-day treatment period is necessary to achieve a clinical result that lasts for several months. Thus, for a device to deliver an effective dosage, it must be retained for at least 7 days. The $25 \%$ tetracycline fiber was physically ejected from the pocket within a few days. To maintain the fiber in the pocket, a bandage, such as a cyanoacrylate adhesive (Drisko et al., 1995) or a periodontal dressing (Vandekerckhove et al., 1997), had to be placed over the treated teeth. Even with this precaution, one group reported that $23 \%$ of the fibers were extruded from the pockets during a 10-day treatment period (Newman et al., 1994). One could surmise that the bulky fibers simply did not fit into the pocket, and that that was the cause for their ejection. However, when a thin ethylcellulose film containing $20 \%$ metronidazole was placed in the pockets, it too was ejected and needed to be anchored to the tooth with a dollop of glass-ionomer cement (Loesche et al., 1996). Likewise, acrylic films containing various antimicrobial agents had to be secured with a periodontal dressing (Addy et al., 1988). In practice, then, non-biodegradable delivery systems need some type of retention mechanism to keep them in place. This mechanism essentially guarantees that the high drug levels will be sustained in the periodontal pocket as long as the device is retained.

This ability of the pocket to eject devices becomes relevant in the context of the biodegradable gel delivery systems that have been commercially developed for doxycycline, metronidazole, and minocycline. The metronidazole gel is almost completely gone after 24 hours (Stoltze, 1995), having decreased from an initial level of $837 \mu \mathrm{g} / \mathrm{mL}$ to I $\mu \mathrm{g} / \mathrm{mL}$ in a little over a day (Goodson, 1994). Its duration of action was only a few days, so it is not surprising that its manufacturer recommended a second treatment after one week. The halflives of the minocycline and doxycycline gels would be longer due to the substantivity of the tetracycline family of agents on tooth surfaces (Goodson, 1994; Polson et al., 1997a). But even with this asset, these gels were reapplied a second time (Timmerman et al., 1996; Polson et al., 1997b), and in one study, a retention rate of $85 \%$ was obtained when a periodontal dressing was used (Polson et al., 1997a).

The small chlorhexidine chips, i.e., $5 \mathrm{~mm} \times 4 \mathrm{~mm} \times 0.3$ $\mathrm{mm}$, containing $2.5 \mathrm{mg}$ of chlorhexidine, reportedly adhere to the tooth and are slowly degraded, thereby maintaining a GCF level of over $100 \mathrm{ppm}$ of chlorhexidine for a seven- to 10-day period. However, no data on the actual number of chips retained for the full seven-day period were reported. In a multicenter study, all sites that remained with 5- to $8-\mathrm{mm}$ pockets were re-treated with the chlorhexidine chips at the three-month visit (Soskolne et al., 1997). Thus, even with this delivery vehicle, re-treatment was deemed necessary.

It seems, then, that the biodegradable gels may need to be re-applied two or more times. This second application negates one of the touted advantages of the biodegradable systems, i.e., that the patient can be treated in a single visit, so that the expense of a second visit to remove the device is avoided. If a gel is lost from the pocket in 1 to 3 days because of ejection and its biodegradability, it would seem all the more prudent to see a patient after a week to ensure that some clinical improvement had occurred.

\section{(2) Choice of agent}

The local delivery vehicles bring such high dosages to the pocket environment that Soskolne (1997) has suggested "that the choice of the antibacterial agent is not critical to the clinical result". This is an interesting concept and implies that the nature of the vehicle determines clinical success. The vehicle with the best retention, ease of use, and lowest cost can be used to deliver any agent. While this possibility has not been directly addressed, there is some evidence that the nature of the agent may be important.

Addy et al. (1988) randomly assigned patients to a root planing group, a "no treatment" group, and groups that received acrylic strips containing a $50 \%$ concentration of either chlorhexidine, metronidazole, or tetracycline. The strips were placed for two consecutive oneweek periods in one site with a probing depth $>5 \mathrm{~mm}$ per patient. A blinded examiner performed the clinical outcome measurements. Inter-group comparisons for both probing depth reductions and gains in attachment showed significantly greater effects for metronidazole and, to a lesser extent, root planing when compared with the chlorhexidine, tetracycline, and "no treatment" groups. These improvements were maintained for at least 14 weeks and were associated, in the metronidazole group, with a sustained reduction in motile organisms and spirochetes. A more detailed bacteriological analysis showed that the tetracycline and metronidazole strips were more effective than chlorhexidine in causing reductions in total anaerobic counts and in the anaerobe/aerobe ratio, but that the tetracycline treatment resulted in the isolation of a large number of resistant organisms (Wade et al., 1992).

Radvar et al. (1996) compared scaling and root planing with scaling and root planing plus one of three commercially available products: $2 \%$ minocycline gel (Dentomycin ${ }^{\circledR}$ ), 25\% metronidazole gel (Elyzol ${ }^{\circledR}$ ), and the $25 \%$ tetracycline fiber (Actisite ${ }^{\circledR}$ ), all inserted according 
to the manufacturers' instructions. A blinded examiner made the clinical measurements. All antimicrobial treatments produced greater mean improvements in probing depth, attachment level, bleeding on probing, and sites with suppuration, compared with scaling alone, but only the tetracycline treatment was statistically better. Loesche et al. (1996) found ethyl cellulose strips containing $20 \%$ metronidazole to be more likely to reduce the need for periodontal surgery than ethylcellulose strips containing $20 \%$ chlorhexidine.

These data suggest that differences may exist among the agents. However, it may be that the differences observed are really due to characteristics of the vehicle, which determines the bioavailability of agents such as chlorhexidine. Thus, the apparent ineffectiveness of chlorhexidine in the acrylic strips (Addy et al., 1988) should not be compared with its apparent effectiveness in the biodegradable delivery system (Soskolne et al., 1997).

\section{(V) Where to Position Antimicrobial Treatments Relative to Debridement}

\section{(A) SySTEMIC AGENTS}

For a systemic agent to be effective, it has to be efficiently absorbed in the intestines, circulate in the vascular system to penetrate the extravascular space, and enter the pocket via the gingival crevicular fluid. If the GCF flow is about $20 \mu \mathrm{L} / \mathrm{hr}$ (Goodson, 1994), this means that, in a 6$\mathrm{mm}$ pocket, about $480 \mu \mathrm{L}$ of GCF containing from 1 to 5 $\mu \mathrm{g}$ of the agent arrives per day to do battle with the $100,000,000$ bacteria that are adhering to the tooth. (These values are based on the assumption that systemic agents achieve GCF levels of 2 to $10 \mu \mathrm{g} / \mathrm{mL}$, that there is about 1 $\mathrm{mg}$ of plaque in a $6-\mathrm{mm}$ pocket, and that $1 \mathrm{mg}$ of plaque contains about 100,000,000 bacteria.) These numbers of bacteria could exhaust the available supply of agent, and could explain why, in the study involving metronidazole in the absence of debridement, a minimal effect of metronidazole was noted (Watts et al., 1986).

It could also explain why periodontal abscesses are sometimes reported in individuals with periodontal disease who are given antibiotics for medical reasons (Topoll et al, 1990). In one report, 10 of 24 patients receiving penicillin developed periodontal abscesses (Helovuo et al., 1993). The prevalence of coagulase-positive staphylococci increased significantly following penicillin therapy, and the prevalence of subgingival Gram-negative enteric rods increased after systemic erythromycin therapy. These authors conclude that, in the absence of mechanical debridement, the exposure of large numbers of subgingival bacteria to low levels of antimicrobials may lead to superinfection with these opportunistic organisms. But it is not just these opportunistic organisms that can overgrow, since many Gram-negative anaerobes isolated from plaque are capable of producing beta-lactamase (Legg and Wilson, 1990; van Winkelhoff et al., 1997). These organisms could be selected for while the patient is on penicillin, and this possibility would be a strong argument against using members of the penicillin family for the treatment of periodontal patients.

To optimize the effect of an antimicrobial agent in the periodontal pocket, one could increase the dosage, as occurs with the local-release delivery vehicles, or decrease the numbers of bacteria on the tooth surface. Both approaches would decrease the ratio of bacteria to antimicrobial agent. If an agent is taken that delivers 5 $\mu \mathrm{g}$ per day to the pocket, then the microbe-to-agent ratio is $20,000,000(100,000,000$ divided by 5$)$. If we assume that scaling of the teeth will reduce bacterial levels in a pocket by $90 \%$, i.e., from $100,000,000$ to $10,000,000$, and the same $5 \mu \mathrm{g}$ of agent is delivered to the pocket, then the microbe-to-antimicrobial-agent ratio is reduced to $2,000,000$ to 1 . If the debridement is thorough, such as would occur with root planing, then the bacterial load may be reduced by $99 \%$, giving a microbe-to-agent ratio of 200,000 to 1

Clearly, after the teeth are debrided, the antimicrobial agent should encounter fewer bacteria in the pocket, and this phenomenon might explain the success of those double-blind studies in which the antimicrobial agent was given after debridement (Tables 2, 3). However, there were clinical improvements in two studies in which metronidazole was given during the first of 4 or 5 visits in which the teeth were debrided (Loesche et al., 1984, 1991). Most of the teeth in these patients would have had high levels of bacteria on their root surfaces when they were exposed to the metronidazole, and the resulting high microbe-to-agent ratio could have minimized the effect of the metronidazole. We evaluated this possibility by repeating the study protocol, but did not dispense the metronidazole until all debridement was completed (Loesche et al, 1992a). An analysis of both studies, in which the only variable was the placement of the metronidazole relative to the debridement, showed that superior results, as measured by reduction in probing depth and gain in attachment, were observed when the debridement preceded the metronidazole (Loesche and Giordano, 1994, 1997). This indicated that the metronidazole was more effective when fewer bacteria were present on the tooth surfaces.

The optimal situation would be for the teeth to be debrided as quickly as possible, and for the patient to take the systemic agent immediately after debridement is completed. This benefit of rapid debridement has been shown in a different context, namely, in the prevention of re-infection with periodontopathogens after treatment with chlorhexidine (Ouirynen et al., 1995). Ten patients were randomly assigned either to a group which received 


\section{Levels of Antimicrobial Agents in the Periodontal Pocket and the Effect of Debridement on Microbe/Agent Ratio}

\begin{tabular}{|c|c|c|c|c|}
\hline \multirow[b]{2}{*}{ Agent } & \multirow[b]{2}{*}{$\begin{array}{l}\text { Levels } \\
\text { in Pocket }\end{array}$} & \multicolumn{2}{|c|}{ Microbe/Agent Ratiod } & \multirow[b]{2}{*}{$\begin{array}{l}\text { Retention } \\
\text { Time (days) }\end{array}$} \\
\hline & & $\begin{array}{l}\text { No } \\
\text { Debridement }\end{array}$ & $\begin{array}{l}\text { After Debridement } \\
(90 \% \text { reduction })^{f}\end{array}$ & \\
\hline $25 \%$ tetracycline & $1700 \mu \mathrm{g} / \mathrm{mL}^{\mathrm{a}}$ & $118,000^{c}$ & 11800 & $7 \mathrm{e}$ \\
\hline $25 \%$ metronidazole & $837^{a}$ & 238,000 & 23,800 & 1 \\
\hline 10\% Doxycycline & $420^{b}$ & 476,000 & 47,600 & $7 e$ \\
\hline $2 \%$ Minocycline & $165^{a}$ & $1,200,000$ & 120,000 & 4 \\
\hline $25 \%$ Chlorhexidine & $150^{b}$ & 1333.000 & 133300 & 7 \\
\hline Systemic metronidazole & $5 \mu \mathrm{g}$ & $20,000,000$ & $2,000,000$ & - \\
\hline
\end{tabular}

a Goodson, 1994.

${ }^{b}$ Greenstein and Poulson, 1998.

${ }^{c} \mu \mathrm{g} / \mathrm{mL}$ divided by 2 to get GCF flow per day of $0.5 \mathrm{~mL}$.

${ }^{d}$ Assume that a 6-mm pocket has $100,000,000$ bacterial cells in the plaque.

e When covered with dressing.

It The bacterial levels are decreased from $100,000,000$ to $10,000,000$. neously if maximal benefits are to be obtained. Since the species which were significantly reduced were anaerobes, a more efficient way of accomplishing this would be to use a systemic agent, such as metronidazole or doxycycline, which would attack all these reservoirs simultaneously. It also raises the possibility that the local-release delivery devices placed within a pocket may not reach these other oral reservoirs of periodontopathic bacteria. This possibility has been recognized by the concurrent usage of a chlorhexidine mouthrinse in open studies involving the $25 \%$ tetracycline fibers (Mombelli et al., 1996; Vandekerckhove et al., 1997).

\section{(B) LOCAL DELIVERY DEVICES}

The local delivery devices, when retained in the pocket, can release the agent at levels in excess of $300 \mu \mathrm{g} / \mathrm{mL} \mathrm{GCF}$ (Goodson, 1994; Soskolne, 1997; Greenstein and Poulson, 1998), and can achieve microbe-to-agent ratios, i.e., from 118,000 to 476,000 bacteria exposed to each $\mu \mathrm{g}$ of agent, in the absence of debridement, that are comparable with those obtained with systemic agents after a thorough debridement, i.e., 200,000 (see above). This concept is illustrated with data obtained with the $25 \%$ tetracycline fiber, which releases about $1700 \mu \mathrm{g}$ of tetracycline per $\mathrm{mL}$ GCF (Table 4). About $500 \mu \mathrm{L}$ of GCF would flow in a $6-\mathrm{mm}$ pocket per day, bringing about $850 \mu \mathrm{g}$ of tetracycline into contact with the $100,000,000$ plaque organisms. This translates to a microbe-to-agent ratio of 118,000 , which is better than the 200,000-to-1 ratio obtained when systemic agents are combined with a thorough, i.e., 99\% efficacy, debridement. The levels of metronidazole released from a $25 \%$ metronidazole gel would be about $420 \mu \mathrm{g}$ per day, giving a microbe-to-agent ratio of 238,000 ; the levels of doxycycline released from the $10 \%$ doxycycline gel would have a microbe/drug ratio of 476,000 . Both of these values would also be comparable with that obtained with systemic agents and a thorough, i.e., $99 \%$ effective, debridement. The $2 \%$ minocycline gel and the chlorhexidine film would have microbe-to-agent ratios which are comparable with the ratio observed with systemic agents and a $90 \%$ effective debridement (Table 4). 
But these favorable ratios exist only when the vehicle is retained in the pocket. The metronidazole gel is gone after 24 to 36 hours (Stoltze, 1995), whereas the tetracycline fiber and the doxycycline gel can be retained for 7 to 10 days with the use of a cyanoacrylate bandage (Drisko et al., 1995; Polson et al., 1997b). Thus, to obtain a complete picture of the agent's efficacy, the length of time that the vehicle remains in place must be accounted for.

In summary, the local delivery devices bring antimicrobial agents into contact with the plaque flora at such high levels that the microbe-to-drug ratio is lower than that which can be obtained by the combination of debridement and systemic agents. These high levels raise a new issue that has profound clinical and cost considerations in periodontal therapy: Do you need to debride the tooth and root surfaces to obtain clinical success, if you can achieve a clinically effective microbeto-agent ratio in the pocket by placing the device in the pocket?

\section{(C) TO DEBRIDE OR NOT?}

The fact that we can even pose this question shows how far our treatment options have expanded in periodontology. Clearly, if a systemic agent is to be used, debridement will greatly improve the clinical outcome to the extent that it should be required. The debridement should be done as quickly as possible prior to the usage of the systemic agent, to provide the most favorable microbe-to-agent ratio. This same consideration should apply to the use of local delivery devices, because it would seem that the agents released by these devices would also benefit from having a more favorable microbe-to-agent ratio as a result of the debridement, i.e., from 11,000 to 133,000 (Table 4). Indeed, the $25 \%$ tetracycline fiber (Goodson et al., 1991; Drisko et al., 1995), the $2.5 \mathrm{mg}$ chlorhexidine chip (Soskolne $e$ al., 1997), and the $2 \%$ minocycline gels (van Steenberghe et al., 1993; Timmerman et al., 1996; Graca et al., 1997), when combined with scaling and root planing, gave statistically superior results in pocket reduction, when compared with those obtained when a placebo was combined with scaling and root planing.

In other multi-center studies, a $25 \%$ metronidazole gel (Ainamo et al., 1992), a 25\% tetracycline fiber (Drisko et al., 1995), and a 10\% doxycycline gel (Polson et al., 1997b), in the absence of scaling and root planing, were compared with scaling and root planing. The fact that the metronidazole gel and the tetracycline fiber seemed to show equivalency to scaling and root planing, and that the doxycycline gel was statistically superior to scaling and root planing, can best be explained by the favorable microbe-to-agent ratios that can be obtained with these agents (Table 4).

But this explanation cannot account for the significant clinical improvement observed in adult patients who were treated with systemic antimicrobials in the absence of debridement (Table 3) (Lopez and Gamonal, 1998). Forty-six patients with active disease, as measured by at least 2 sites showing $\geq 2 \mathrm{~mm}$ attachment loss, were randomly assigned in a double-blind study to groups which received either metronidazole and amoxicillin for one week, or to a placebo group. At 2 and 4 months after treatment, the antimicrobial group exhibited significantly reduced probing depths and increased attachment levels compared with the placebo group. This difference reflected no change or deterioration in the placebo group compared with an improvement in the treated group. The authors attributed this improvement to the combination of agents used, but for this to be true, groups which received only metronidazole or amoxicillin needed to be included.

This result, as well as those obtained with the local delivery vehicles, challenges the fundamental premise of periodontal treatment-namely, that the teeth have to be physically debrided-and questions the 2000-yearold role of calculus in the etiology of periodontal disease (Mandel, 1995). It will be hard to persuade clinicians that it is not necessary to remove calculus, unless the paradigm has truly changed, i.e., that one may not need to "instrument" the root surface to improve the periodontal condition. An indication that this is possible was observed when the plaque levels of institutionalized teenagers with mental handicaps could be suppressed for a year in the absence of toothbrushing, by applications of a $5 \%$ kanamycin paste to the dento-gingival surfaces at five-week intervals (Loesche and Nafe, 1973). Also, in some studies, pocket sites that received only the antimicrobial agent showed improvement comparable with that found in sites receiving scaling and root planing (Lindhe et al., 1983; Addy et al., 1988).

\section{(VI) How Do We Know that an Antimicrobial Agent Works?}

An antimicrobial agent works if it improves the health of the patient. The types of clinical studies reported in the periodontal literature will be discussed in terms of their design, and as to whether their outcomes reflected tangible benefits to the patient.

\section{(A) Open vs. DOUble-BLIND STUdies}

The most common clinical studies are open studies, in which either the investigator or the patient or both know what treatment the patient received. Open studies can introduce various biases and confounders which are not randomly distributed between/among the treatment groups, and these could lead to misinterpretation of the clinical results. Consider the situation in an open study involving patients with LJP, or with refractory periodontitis, in which the probing depths and attachment levels 
are measured before and after treatment. The attachment level prior to treatment for a given pocket is exactly $5.5 \mathrm{~mm}$, halfway between the $5-\mathrm{mm}$ and $6-\mathrm{mm}$ markings on the periodontal probe. The examiner knows that the patient hasn't yet been treated, and he may "round up" the $5.5 \mathrm{~mm}$ to $6 \mathrm{~mm}$ for the baseline recording. After treatment, the attachment level remains exactly at 5.5 $\mathrm{mm}$, but since the examiner knows that the patient has been treated, s/he may "round down" the reading to 5 $\mathrm{mm}$. A $1-\mathrm{mm}$ gain in attachment appears on paper, when there has been no change in the actual attachment level.

This type of unintentional bias on the part of the examiner means that caution must be exercised in the interpretation of positive results from open studies. It was open studies that showed a benefit of tetracycline treatment in LJP patients (Slots and Rosling, 1983; Lindhe and Liljenberg, 1984; Mandell et al., 1986; Novak et al., 1991), whereas the only double-blind study in LiP patients showed no advantage for a two-week treatment with doxycycline (Asikainen et al., 1990). If tetracycline was effective, as the open studies indicated, then doxycycline should also have been effective. Subsequently, two groups (Saxén and Asikainen, 1993; Gunsolley et al., 1995) have reported that debridement alone was adequate to manage LIP patients, essentially confirming the results of the double-blind study, which showed no benefit of doxycycline over debridement.

While open studies can provide insights into the design of definitive studies, they should not serve as the basis for treatment decisions. The medical literature is replete with open studies which showed the therapeutic efficacy of medications that were subsequently proven, in double-blind studies, to be ineffective (Chalmers et al., 1983). Double-blind studies in which neither the patients nor the investigators are aware of the treatments being rendered are the "gold standard" in clinical trials, because any biases, measurement errors, and other confounders are randomly distributed between/among the treatment groups. It is for this reason that only double-blind clinical trials are featured in this review (Tables 2, 3).

An important exception would be studies involving the use of vehicles or devices that can be placed within the periodontal pocket in which the clinical trials were single-blind, i.e., the patients were randomly allocated to the treatments, and a blinded examiner measured the treatment outcomes. Given the split-mouth design of these studies, and the nature of the delivery agent, i.e., a fiber, film, or gel delivered to the treatment site, it would be difficult to keep either the patient or the treating clinician ignorant of which sites were treated with the agent. However, the external examiner, if properly shielded from the treatment events, should be able to record outcome measurements objectively, thereby increasing the validity of these studies.

\section{(B) TRue vS. SURROGATE CLINICAL OUTCOMES}

\section{(1) Tooth loss, a true clinical outcome}

The best clinical outcome for a periodontal patient following treatment would be the retention of formerly diseased teeth for a lifetime. The measurement of tooth loss following treatment would be a clinical outcome that would be appreciated by the patient and would meet the definition of a true clinical endpoint (Hujoel and DeRouen, 1995). Several clinicians have described the long-term survival of teeth following periodontal treatment in their private practices (Hirshfeld and Wassermann, 1978; McFall, 1982; Meador et al., 1985). These case reports indicate that about 73 to $83 \%$ of patients retain all or most of their teeth as a result of treatment. Accordingly, they provide estimates on tooth loss rates following debridement/surgical treatments which can be used to evaluate new or different treatment modalities. These studies also identified teeth with deep pockets, furcation involvement, extensive bone loss, or marked mobility as having a questionable or "hopeless" prognosis because they did not respond to treatment.

There appears to be only one clinical trial that has used tooth loss as an outcome variable (Hujoel et al., 1997). This is because of the prohibitive expense of conducting studies in which large numbers of subjects would have to be followed for several years for this outcome to be assessed. The utility of tooth loss as an outcome in many studies is undermined by the fact that the "hopeless" teeth, whose response to treatment could be a sensitive indicator of an effective treatment, have often been extracted prior to any treatments. This means that secondary, or surrogate, clinical outcomes are used to evaluate the success of treatment in these studies. The most widely used surrogate outcomes are reduction in probing depth and gain in attachment, although as many as 153 surrogate endpoints have been reported in the periodontal literature (Hujoel and DeRouen, 1995).

\section{(2) Changes in probing depth and attachment levels (surrogate outcomes)}

Improvements in probing depths and attachment gain were introduced as clinical endpoints in the 1970 s (Kaldahl et al., 1993), and are based on observations that teeth with deep pockets and high levels of attachment loss are likely to have periodontal disease, to be loose. and, if untreated, are at risk to develop abscesses requiring extraction. Any improvements in these parameters would be expected to restore periodontal health Thus, they appear to be reasonable surrogates for lost teeth, but the relationship between probing measurements and tooth loss is unknown (Hujoel and DeRouen, 1995). 
Hujoel et al. (1997) sought to validate probing attachment measurements against tooth loss in older patients participating in a clinical trial involving education materials, oral hygiene instructions, periodic prophylaxis, and the use of chlorhexidine rinses. There was a strong statistical correlation between loss of attachment and tooth loss. However, in a logistic regression analysis, the loss of attachment explained only $6 \%$ of the tooth loss, which is far below the accepted guideline that a valid surrogate should explain at least $50 \%$ to $75 \%$ of the true endpoint. This indicated that probing depths and attachment levels do not measure the potential for tooth loss. Rather, they seem to be measuring disease progression that falls short of tooth loss, and whether they are valid surrogate outcomes for tooth loss, or for measuring the efficacy of an antimicrobial agent, remains to be determined.

The use of nonvalidated surrogate outcomes in medicine, especially in chronic diseases, has on occasion led to mistakes, such as the use of drugs to reduce ventricular arrhythmias (Hallström, 1992). Ventricular arrhythmias are associated with increased mortality, so drugs which reduced arrhythmias were sought. The drugs which successfully suppressed the cardiac arrhythmias were estimated to have caused about 8,000 deaths per year before they were withdrawn from use. The concern then, to quote Hujoel and DeRouen (1995), is "in the absence of validated surrogates, the choices in trying to obtain definitive answers are to design studies that use true endpoints (such as tooth loss) which may result in large, long and expensive studies; or to continue using nonvalidated surrogates and pray that they won't lead to the kind of incorrect and even dangerous conclusions observed in other areas."

\section{(3) Sample size determinations in clinical trials}

The use of probing measurements as an outcome has an effect on the sizes of the treatment groups. The measurement of attachment levels has a standard deviation of $\pm 1 \mathrm{~mm}$ (Pihlstrom, 1992), and this measurement error, i.e., $33 \%$ in a $6-\mathrm{mm}$ pocket, decreases the ability to show a treatment effect between/among groups. As a result, it would increase the need for a larger sample size for statistical significance to be shown. Power calculations indicate that about 25 to 30 patients would be needed in each treatment group, to have a difference of $1 \mathrm{~mm}$ in attachment level to be significant between/among the groups. In the majority of the clinical studies, there were 15 or fewer subjects in each treatment group, so that only a very obvious difference between/among the groups would be significant. Thus, the possibility of a Type 2 error or false negative result is great, i.e., reporting no treatment effect when indeed there may be one.

This possibility of a Type 2 error can be illustrated by a double-blind study of systemic metronidazole in individuals with mental retardation. In this study, the authors concluded that "the use of adjunctive metronidazole in a population of retarded adolescents provides no additional benefits to conventional treatment alone" (Clark et al., 1983). Twenty-three subjects were included, and the data on attachment change were reported on two sites per patient. If power calculations are applied to the results shown in Table 2, page 661 of that report, then only 15 patients per group, or a total of 30 subjects $(60$ sites), were needed to have an $80 \%$ probability of showing a $5 \%$ significance between/among the groups. Thus, with a few more subjects, the study would have had enough power to reject the null hypothesis that there were no differences between/among the treatment groups. As it was, the observed trend indicated that the one week of metronidazole treatment was beneficial to these subjects.

The importance of sample size was demonstrated in another study involving metronidazole (Watts et al., 1986). In this investigation, no debridement procedures were provided, and the patients were randomly assigned to either the metronidazole or the placebo group. The study was stopped after two years, because all the dropouts were in the placebo group, so the 13 patients in the metronidazole group were compared with only seven in the control group. The trial demonstrated a "clear but limited difference" in favor of the metronidazole which was found "despite the imbalance in recruitment to experimental and control group, a tendency which could have contributed to possible Type 2 error, that is failing to find a difference which really existed "

The problem of small sample size can be partially addressed by the statistical technique known as metaanalysis. The meta-analysis represents a re-analysis of published data in which results from several studies are combined if they meet predetermined inclusion criteria. The added statistical power obtained with a larger sample size then improves the chances that statistical significance can be shown where previously none was found. Meta-analysis has been applied to published studies of tetracycline, and it was concluded that there was no scientifically valid evidence that tetracycline was of value in periodontal treatment (Hayes et al., 1992). A meta-analysis of metronidazole showed that metronidazole was effective in reducing pocket depths and increasing attachment levels in pockets $>4 \mathrm{~mm}$ for several months after treatment had been completed (Elter et al., 1997).

The small sample size often reflects the lack of funding for clinical studies involving generic agents such as tetracycline, metronidazole, minocycline, and doxycycline. No commercial sponsor will invest resources for an agent in which there is no proprietary control. The slowrelease delivery systems developed for local treatment 
within a pocket are under patent protection and have resulted in a considerable investment by their developers in multi-center clinical trials. These studies are planned in consultation with the FDA, and power calculations are done so that adequate sample sizes are achieved. A new problem in data interpretation can emerge, since now the difference between/among the treatment groups can be statistically significant but may be of minimal clinical relevance, i.e., differences of 0.2 to $0.3 \mathrm{~mm}$ gain in attachment between/among treatment groups (Ainamo et al., 1992; Soskolne et al., 1997).

\section{(4) Elimination and/or reduction of the periodonto- pathogens from the plaque (surrogate outcomes)}

If specific periodontopathic bacteria are etiologically involved in periodontal disease, then the efficacy of treatment could be assessed by the disappearance of this organism(s) from plaque samples. The elimination of a pathogen from the host tissue is a valid clinical outcome in medicine, and such an outcome would align periodontal treatments with the established protocols of infectious disease. This assumes that the correct periodontopathogen is being monitored. But which organism is the correct one? Most likely, periodontal disease is a polymicrobial infection, and therefore no single species can be considered as "the periodontopathic species". Our previous discussion indicated that the majority of the evidence implicated the overgrowth of a limited number of anaerobes as the most likely periodontopathogens, so that the monitoring of these bacteria could be used to measure the efficacy of antimicrobial treatments.

Most anaerobes cannot be reliably or inexpensively monitored by culture methods. But the levels of spirochetes can be determined at chairside by either darkfield or phase-contrast microscopy. Many antimicrobial agents can reduce the levels of spirochetes in plaque samples, sometimes to undetectable levels, but with time they return, albeit at lower levels. The most successful treatments in suppressing spirochetes have been described by Keyes and colleagues (Keyes et al., 1978; Rams et al., 1984). After the initial suppression of the spirochetes by debridement and systemic antimicrobials, the patients are instructed to brush their teeth and to irrigate any periodontal pockets with various antimicrobial agents. The levels of spirochetes in the plaque sample are then used to monitor the efficacy of treatment, and to adjust the intensity of the antimicrobial regimen.

Other groups have monitored treatment efficacy by the reduction of black-pigmented species, such as P. gingivalis and $\mathrm{P}$. intermedia, from plaque samples and observed in most cases a significant reduction in levels that lasted for several months (Loesche et al., 1984, 1991, 1992a; Walker and Gordon, 1990; Kulkarni et al., 1991; van Winkelhoff et al., 1992; Socransky and Haffajee, 1993; Haffajee et al., 1995; Mombelli et al., 1996), Even when all the teeth were debrided within a 24-hour period and chlorhexidine preparations were applied to the pockets, tongue, oral mucosa, and tonsils, P. gingivalis was eliminated from only six of 10 patients for up to 2 months (Bollen et al., 1998).

Several investigators have used the decline in plaque levels of A. actinomycetemcomitans as a means of measuring the efficacy of treatment. In these open studies, tetracycline was combined with surgery (Mandell $e t$ al, 1986; Mandell and Socransky, 1988; Renvert et al., 1996) or was given from three to eight weeks (Slots and Rosling, 1983; Christersson and Zambon, 1993) without A. actinomycetemcomitans being eliminated from all plaque samples. Only a combination of metronidazole and ampicillin, again in open studies, has been able to suppress A. actinomycetemcomitans in the majority of plaque samples (van Winkelhoff et al., 1992).

The difficulty in eliminating spirochetes or A actinomycetemcomitans, P. gingivalis, and P. intermedia from plaques suggests that the elimination of these species is not a realistic treatment outcome. Many, if not all, of the periodontopathic bacteria are so prevalent in plaque samples that they could be considered as members of the normal flora. They could also be living in reservoirs such as the tongue and tonsils. A systemic agent might have access to all these locations, but a locally delivered agent probably would not. This would be a disadvantage for the locally delivered agents and is the reason the chlorhexidine rinse is recommended when tetracycline fibers are used (Flemmig et al., 1996; Mombelli et al., 1996; Vandekerckhove et al., 1997).

This persistence of the periodontopathic species probably relates to the underlying microbial ecology of the plaque and the relationship of these species to the host. Rosebury (1962) introduced the concept of an amphibiotic state to describe those infections attributed to the overgrowth of bacterial species that are normally present in the indigenous flora, but at low levels. Certain changes in or on the mucous membranes allow these species to be selected for, and as a result of this overgrowth, they cause an endogenous infection, resulting in clinical disease. Medical examples of endogenous infections would be the several types of diarrhea diseases that occur as a result of malnutrition, vaginal infections due to yeast, superinfections that follow the usage of antibiotics, e.g., a Clostridium difficile infection after the use of clindamycin.

Dental caries would be an endogenous infection due to the selection of the mutans streptococci by frequent sucrose ingestion (Loesche, 1993a). It is likely that periodontal disease is an endogenous infection due to the 
overgrowth of anaerobic species when plaque accumulates at the dento-gingival margin and in periodontal pockets. An additional selection factor for periodontopathic bacteria would be their ability to utilize nutrients that are made available as a result of tissue inflammation (Loesche, 1993b). Host products such as hemin, menadione, progesterone, estradiol, acetylmuramic acid, spermine, alpha-2 globulin, and ceruloplasmin seem to be essential growth factors for P. gingivalis, B. forsythus, T. denticola, and $P$. intermedia. In a sense, these organisms are host-dependent for their nutrients and, as a result, are very difficult to eliminate from plaques. Because the periodontopathic species can be considered as amphibiotic, it will be difficult to eliminate them from plaque samples. A more realistic treatment endpoint would be to reduce the levels of the periodontopathic species to below a certain threshold level, but these levels are not reliably known

\section{(5) Reduced need for surgery}

In our first metronidazole double-blind study, we observed a significant reduction in probing depth and gain in attachment following debridement in the metronidazole group relative to the placebo group (Loesche et al., 1984). When these patients were re-examined after one year to determine how long the beneficial effects of the metronidazole would last, many of the pockets which had shown clinical improvement had subsequently been eliminated by surgery. This meant that the benefits measured by probing depths and attachment level measurements were either so fleeting that they could not prevent surgery from being performed, or that surgery was performed because of the residual pocket depths, even though the tissue appeared healthy.

This situation led us to re-assess what would be a meaningful clinical outcome both for the patient and for the clinical investigation. Since surgery can be a deterrent for the patient, due to both cost and perceived discomfort (Meador et al., 1985; Matthews and McCulloch, 1993), a decision was made to determine whether successful treatment would reduce the need for surgery. We also stopped the a priori extraction of "hopeless teeth" so that these teeth could be used as indicators to monitor the effect of treatment. These outcome measurements had the immediate advantage of reducing the cost and discomfort of surgery to the patient, and because teeth were at least initially spared from extraction, approached the definition of a true outcome for the patient. This reduced need for surgery could simply be surgery delayed, and as a precaution against the premature report of success based on an ephemeral outcome, we withheld the publication of our findings until we had one or more years of follow-up on these patients (Loesche et al. 1991, 1992a, 1996)
The decision as to whether a tooth needs surgery or extraction is made daily in clinical periodontology, yet the parameters for that decision-making process have never been standardized. We established guidelines for the determination of surgical need, or extractions, which were based upon probing depths and attachment levels; the presence or absence of bleeding or exudate; the nature of the root topography and bony defects as seen in radiographs; the nature and extent of any furcation involvement; the magnitude of tooth mobility; and whether access would be adequate for thorough root instrumentation (Loesche et al., 1991, 1992a). Using these guidelines, two clinicians, each with over 30 years of clinical experience, independently examined the patients, and their findings were used to determine the measurement error (Loesche et al., 1996). The inter-examiner correlation coefficient for surgical needs was $r=$ 0.94 , and the intra-examiner correlation coefficient was $r$ $=0.98$. The tooth-by-tooth $\%$ agreement was $90 \%$, and the kappa statistic was 0.85 .

The reason for this high level of agreement could be the convergence of so many clinical parameters on a single yes/no decision, i.e., probing and attachment measurements, bleeding on probing, mobility, furcations, tooth type, tissue appearance, and bone levels on radiographs. As such, this measurement is much richer than the one-dimensional attachment levels or probing depth scores that are usually reported as outcome variables in clinical trials of antimicrobial agents.

\section{(C) THE INTERPRETATION OF STUDIES WHICH USE SURROGATE ENDPOINTS}

\section{(1) Clinical relevance of surrogate endpoints}

How do you interpret the success of clinical trials that rely upon surrogate outcomes such as gain in probing attachment levels, if no one knows what this gain means in terms of tangible benefit to the patient? Presumably, a gain in attachment level results in increased retention of the tooth in the mouth, but Hujoel et al. (1997) concluded that "probing attachment levels can be ruled out as being anything more than a weak surrogate marker for tooth mortality". While there is no doubt that improvements in attachment levels as a result of treatment are beneficial, the meaning of this benefit cannot be assessed by the probing measurements themselves.

For example, Quee et al. (1987) showed that the Rodogy $1^{\circledR}$-treated group compared with the placebo group (both groups received scaling and root planing) exhibited a significant whole-mouth average gain in attachment of $0.67 \mathrm{~mm}$. Yet they cautioned that this difference was not necessarily of biological significance and speculated whether the placebo group would have undergone periodontal breakdown sooner than the 


\section{Effect of Scaling/Root Planing and Either Metronidazole or Placebo} on Clinical Outcomes

$\begin{array}{lll}\text { Scaling \& Root } & \text { Scaling \& Root } & \text { Significance } \\ \text { Planing \& } & \text { Planing \& Placebo } & \\ \begin{array}{l}\text { Metronidazole } \\ \text { ( } n=33 \text { patients) }\end{array} & \text { ( } n=39 \text { patients) }\end{array}$

Number of Teeth Needing Surgery/Patient

\begin{abstract}
At baseline
At completion Change
\end{abstract}

Sites with

Initial Probing Depth

$\leq 3 \mathrm{~mm}(21-121)^{d}$

4 to $6 \mathrm{~mm}(16-74)$

$\geq 7 \mathrm{~mm}(1-51)$

Sites with

Initial Probing Depth

$\leq 3 \mathrm{~mm}(21-121)$

4 to $6 \mathrm{~mm}(16-74)$

$\geq 7 \mathrm{~mm}(1-51)$

a Two-factor ANOVA.

b Weighted ANOVA.

' Average \pm standard deviation.

d Range of sites in each category per patient.

Adapted from Loesche and Giordano, 1994.
(2) Reduced need for surgery as a relevant clinical outcome

A reduction in surgical needs has been used as a clinical endpoint in three double-blind studies involving metronidazole (Loesche et al., 1991, 1992a, 1996). A sparing of teeth from extraction is a true endpoint, since it prevents the immediate loss of the tooth and whatever adverse consequences this might have for masticatory function and esthetics. A reduction in the need for periodontal surgery has an immediate clinical relevance, since it provides the patient with a tangible benefit, the avoidance of surgery, which benefit could encourage the patient to continue treatment and/or allow him/her to afford treatment. If periodontal disease is a risk factor for heart disease (DeStefano et al., 1993; Mattilla et al., 1995; Beck et al., 1996; Loesche et al., 1998a), then anything that encourages the patient to obtain periodontal treatment would be an important benefit.

The combined data from the first two studies showed that, in terms of surgical need, there was an average reduction of 7.1 teeth per patient in the metronidazole group,

Rodogy $]^{\circledR}$-treated group. That apparently would have been a clinically relevant outcome, since it indicated that the gain in attachment levels halted or slowed disease progression. McCulloch et al. (1990) used disease progression as their clinical outcome, i.e., doxycycline reduced the rate at which refractory patients developed abscesses and lost teeth.

The double-blind clinical trials of locally delivered tetracycline (Drisko et al., 1995), minocycline (van Steenberghe et al., 1993), doxycycline (Polson et al., 1997b), and chlorhexidine (Soskolne et al., 1997) were sufficiently powered with large numbers of subjects, so that average whole-mouth differences of 0.2 to $0.6 \mathrm{~mm}$ in attachment levels between the test and placebo groups were statistically significant. But how do you assign clinical significance to these modest gains in attachment? Soskolne (1997) speculated that by decreasing loss of attachment, "controlled subgingival antibacterial therapy should reduce the sites needing surgery by $50 \%$ ". This implies that a reduction in surgical needs would be a tangible attribute of the clinical relevance of improvements in attachment levels. and of 2.4 teeth per patient in the positive control group (difference significant at the $\mathrm{p}=0.002$ level; Table 5) (Loesche and Giordano, 1994). This reduction was associated with a significant reduction in pockets that were initially $>6 \mathrm{~mm}$, and a significant gain in attachment at all pocket depths compared with the control (Table 5). In the third study, the goal of treatment was to determine how much surgical need could be avoided by a protocol that used either metronidazole or doxycycline in the first round of treatment, with the type of treatment rendered thereafter-e.g., re-treatment with systemic agents or local delivery of metronidazole or chlorhexidine-dependent upon the number of teeth still requiring surgery or extraction. Ninety patients, including patients with refractory and early-onset periodontitis, who at entry into the study had an average of 8.7 teeth/patient in need of access surgery or extractions, completed the treatment phase of the study. Overall, $81 \%$ of these patients and $93 \%$ of the 640 teeth initially recommended for access surgery did not need this surgery. Sixty-six percent of the "hopeless" teeth, initially recommended for 
extraction, needed neither extraction nor access surgery (Table 6).

These studies indicate that most surgical procedures could be prevented by a combined debride ment/antimicrobial approach. This begs the question, "How long should a treatment benefit last in order for it to be considered a real benefit"? In the first two studies, the patients were followed for at least 18 months to determine if the observed reduction in surgical needs could be sustained (Loesche et al, 1991, 1992a). The patients who had been treated with metronidazole fared better than those who had been in the positive control group. Sixteen percent of the patients in the positive control group relapsed, in that they had 4 or more teeth needing surgery, compared with $8 \%$ of the patients in the metronidazole group (Loesche and Giordano, 1997). At the entrance to the maintenance phase, there were 213 teeth that had been spared from surgery or extraction in the metronidazole patients. During the next 18 months, 19 of these teeth needed surgery or extraction, while the other 196 teeth remained healthy. In the positive control patients, 97 teeth relapsed. Thus, even in the maintenance period, a residual benefit of the initial metronidazole treatment was observed, indicating that a sustained benefit had been conferred by the metronidazole treatment.

in the third metronidazole study, 73 of the 90 patients who completed the

study did not receive any surgery or extraction during the active treatment phase, so that one might expect that this legacy of surgical need would come due sometime during the maintenance phase. Eighty-two of these 90 patients have been seen at least once in the mainte-

\section{TABLE 7}

\section{The Number of Teeth Needing Surgery or Extraction in the 1- to 5-year Period Following Initial Antimicrobial Treatment (Loesche et al., 1996)}

nance phase; 63 patients have been examined twice, and 50 have been examined three times. Very few teeth have needed either surgery or extraction during the first 4 years of recall (Table 7). These 82 patients were initially treatment-planned as having 8.9 teeth/patient needing surgery or extraction. In reality, only $9 \%$ of these teeth actually received surgery or extraction during the active treatment phase, and another $13 \%$ received surgery or extraction during the following 1 to 4 years of the maintenance phase. Forty-five patients $(56 \%)$ have not needed surgery, and eight patients (10\%) have accounted for about $50 \%$ of the teeth needing surgery or extraction. These results indicate that over $70 \%$ of teeth that were initially spared surgery/extraction have remained free of surgical intervention during the first 1 to 4 years of the maintenance phase. This would appear to be a tangible benefit to the patients, and indeed the patients indicate this in their responses on a questionnaire evaluating patient satisfaction with treatment.

\begin{tabular}{llllll}
\hline Treatment Stages & $\begin{array}{l}\text { No. of } \\
\text { Patients }\end{array}$ & $\begin{array}{l}\text { No. of Teeth/ } \\
\text { Patient }\end{array}$ & $\begin{array}{l}\text { Number of Teeth/Patient Needing } \\
\text { Extractions }\end{array}$ & Total \\
\hline At baseline & 82 & 23.7 & 7.1 & 1.7 & 8.9 \\
At completion of treatment & 82 & 23.3 & 0.3 & 0.8 & 1.1 \\
At 1 st recall & 82 & 22.8 & $0.3^{a}$ & $0.8^{a}$ & $1.1^{a}$ \\
At 2nd recall & 63 & 22.5 & 0.3 & 1.1 & 1.4 \\
At 3rd recall & 50 & 22.4 & 0.4 & 1.2 & 1.6 \\
\hline
\end{tabular}

a Cumulative number of new teeth needing surgery or extraction during the recall period (the 1.1 total teeth/patient needing surgery or extraction at completion of treatment is not included in this number). 


\section{(D) Patient compliance}

If antimicrobial agents are to be used in the treatment of periodontal infections, their efficacy will be dependent upon patient compliance. This is an important issue when the results of treatment are evaluated, because an unsatisfactory result could indicate either an ineffective agent or a non-compliant patient. An effective agent that is not used by the patient is of little value.

\section{(1) Systemic agents}

Patient compliance with the unsupervised usage of prescription medication is a serious concern in medicine (Greenberg, 1984; Eisen et al., 1990) and is a major confounder of clinical trials (Freedman, 1990). Patient noncompliance is a function of socio-economic factors (Nagasawa et al., 1990), the clarity of the instructions (Stewart and Caranasos, 1989), and the daily frequency at which the medication should be taken (Cockburn et al., 1987; Eisen et al., 1990). As an example of the latter, non-compliance with antihypertensive medications was $41 \%$ on a $3 x$ daily regimen, but only $16 \%$ on a once-aday regimen (Eisen et al., 1990). This would indicate that in studies evaluating systemic antimicrobial agents in periodontal disease, patient compliance will decrease as a function of the number of tablets that should be taken daily and the length of the treatment. The best results should be obtained with antimicrobials that are the easiest to take.

This consideration would support the usage of doxycycline, which needs to be taken only once a day for at least two weeks (McCulloch et al., 1990; Loesche $e t$ al., 1996), and would encourage more studies with azithromycin, which appears to be effective after one tablet is taken daily for only three days (Sefton et al., 1996). It would discourage the usage of medications that need to be taken multiple times a day, such as tetracycline (four times a day), Rodogyl ${ }^{\circledR}$ (two tablets three times a day), and combinations of metronidazole and amoxicillin (two tablets three times a day).

Bottles with metronidazole carry a label warning the patient not to consume alcoholic beverages, which label is likely to discourage compliance. We developed a spirochete and BANA assay to measure patient compliance with metronidazole (Loesche et al., 1993). We gave patients metronidazole under supervision and demonstrated that the plaque spirochetes either could not be detected or had greatly decreased at 1 and 8 days after patients stopped taking the medication. We chose spirochetes as our indicator organism, since they are sensitive in vitro to $<0.1 \mu \mathrm{g} / \mathrm{mL}$ metronidazole (Cheng et al., 1985), and these levels are easily achievable in the GCF (Britt and Pohlod, 1986). Spirochetes are not known to be resistant to metronidazole, so that if their levels remained unchanged in plaque samples in patients assigned to the metronidazole group, the patient was considered non-compliant. We also monitored compliance by the conversion of plaque samples from BANA-positive to BANA-negative, on the basis that the BANA-positive species, P. gingivalis, B. forsythus, and T. denticola, are sensitive to low levels of metronidazole and are not known to have developed resistance to this agent (Listgarten et al., 1993; Larsen and Fiehn, 1997).

We then evaluated patient compliance by retrospectively monitoring the response of plaque spirochetes and the BANA test in patients involved in a double-blind clinical trial in which the metronidazole was taken $250 \mathrm{mg}$ tid for one week (Loesche et al., 1993). Seven of the 18 patients in the metronidazole group appeared to be non-compliant, since the levels of spirochetes showed no change or actually increased, and the BANA test remained positive (Loesche $e t$ al., 1993). All 18 patients claimed to have taken their medication and brought back empty medication bottles. When the clinical data were re-analyzed according to whether the patient was compliant or non-compliant, the number of teeth requiring periodontal surgery was decreased by 8.3 teeth in the compliers, but by only 3.6 teeth in the non-compliers.

These findings suggested that $40 \%$ of the metronidazole patients were non-compliant, but despite this, and the small sample size ( $n=18$ patients), the reduction in the need for surgery for the metronidazole patients compared with the placebo patients was significant (Loesche et al., 1991). This indicated that metronidazole was an extremely effective drug in treating anaerobic periodontal infections. For compliance to be improved, the metronidazole can be taken $500 \mathrm{mg}$ twice a day, or a slow-release metronidazole tablet (G.D. Searle, Chicago, IL, USA), to be taken only once a day, can be used.

\section{(2) Locally delivered agents}

The development of local delivery vehicles solves the problem of patient compliance, since the vehicles are professionally placed, thereby negating any reliance upon the patient to take the medication. However, the duration of treatment effect, which could be considered as a manifestation of compliance, will vary according to whether these vehicles are retained for the duration of treatment. If these vehicles are lost, then the pocket was not exposed to the full dosage, and in a sense the patient could be considered as non-compliant.

This argument cannot be applied to the biodegradable vehicles, because if the vehicle is not present at one week, it could have been lost from the pocket as a result of those forces which eject fibers and films, or because it 
was lost via its intended biodegradation. It is not known if vehicles that are in the process of being biodegraded are lost more quickly than vehicles that are not biodegradable. In this regard, the $10 \%$ doxycycline gel was retained in place with a periodontal dressing (Polson et al., 1997a), so that these teeth could be considered, in a sense, compliant. The chlorhexidine-containing chip reportedly is retained for 7 to 10 days (Soskolne, 1997), and pockets so treated could be considered compliant. The $25 \%$ metronidazole gel (Stoltze, 1995) and the $2 \%$ minocycline gel may not remain in situ long enough for the treated pockets to be considered compliant.

\section{(VII) Changing the Paradigm}

\section{(A) The antimicrobial MANAGEMENT OF PERIODONTAL DISEASE}

According to the Specific Plaque Hypothesis, a measurable amount of periodontal disease is due to the overgrowth of specific bacterial types. This indicates that in the presence of clinical disease and the documented overgrowth of these periodontopathic species, antimicrobial treatments involving both mechanical procedures and chemical agents can be used for short periods of time to achieve long-term effects. The established treatments are based upon a non-specific plaque overgrowth paradigm, which, if therapy is maintained on a periodic basis for a lifetime, can provide satisfactory results for about $80 \%$ of periodontal patients. In order for the Specific Plaque Hypothesis to change the existing periodontal treatment paradigm, it would have to offer advantages beyond those provided by the debridement/surgical paradigm.

Both paradigms are antimicrobial, in that debridement is used to limit the numbers of bacteria that accumulate on the tooth surfaces. They differ in the treatment of patients with advanced disease. The Non-specific Plaque paradigm states that, for adequate debridement of the tooth/root surfaces when there are deep pockets, the pockets need to be surgically eliminated, so that the patient can practice good oral hygiene on these newly accessible tooth/root surfaces. The surgery is often accompanied by the use of systemic antimicrobials, to prevent post-operative infections. If the patient cannot maintain clean tooth/root surfaces after the surgical approach, and the diseased pockets return, then systemic antimicrobials are used in a rescue or salvage mode. Thus, in the Non-specific Plaque Paradigm, there would appear to be no contra-indications for the use of antimicrobial agents, provided that this use coincides with the surgical procedures, or is used when surgery fails (Fig.) (Genco, 1991; Goodson, 1994; Anonymous, 1996a,b).

The Specific Plaque paradigm, in contrast, recommends that the short-term usage of antimicrobial agents, in combination with debridement, should precede any surgical intervention (Fig.). It requires that one identify the periodontopathic flora prior to any treatment and then use the appropriate antimicrobial agent. Over 20 bacteriological studies have implicated the overgrowth of anaerobic species as being statistically associated with advanced forms of periodontal disease. This finding would call for the short-term usage of antimicrobial agents directed against anaerobic members of the flora. Metronidazole and doxycycline have been shown to be effective in double-blind studies, and the Specific Plaque Hypothesis would recommend their use in patients diagnosed with anaerobic infections. The Specific Plaque Hypothesis 
would reserve the surgical approach for those instances when the antimicrobial approach fails (Fig.).

The two paradigms use the same modules of treatment but differ operationally in the sequencing of these modules. It is this sequencing that has profound implications in the management of periodontal disease. If periodontal disease behaves as a treatable infection, then an antimicrobial approach would reduce the need for labor-intensive surgical procedures, thereby offering the patient a less expensive treatment protocol. This advantage alone should be sufficient to explore treatments based upon the Specific Plaque paradigm. But will a profession embrace a specific infection treatment paradigm after years of apparent success with a debridement/surgical paradigm? The answer is probably "yes", for the following reasons:

The data on the microbial etiology of most forms of periodontal disease are overwhelming and have led to double-blind studies which have shown that advanced forms of periodontal disease can be successfully treated by short-term usage of metronidazole and doxycycline. But information on the success of these agents has not been widely communicated within the dental community, partly because it challenges the traditional debridement/surgical treatment paradigm, and partly because these agents are generic drugs without any industry support. A recent review in the medical literature states that "if metronidazole were a patented antibiotic, the manufacturer would almost certainly be willing to put substantial marketing resources into convincing the clinical community that antibiotic treatment of periodontal disease was less invasive, cost-effective, cosmetically superior, and less risky than surgery" (Hay and Yu, 1999).

While industry support is missing for these generic antimicrobials (although it might be there for azithromycin; Zithromax ${ }^{\circledR}$ ), it is there for the localrelease delivery vehicles for tetracycline (Actisite ${ }^{\circledR}$ ), chlorhexidine (PerioChip ${ }^{\circledR}$ ), doxycycline $\left(\right.$ Atridox $\left.^{\circledR}\right)$, and metronidazole $\left(\right.$ Elyzol $^{\circledR}$ ). Once the benefits of this local treatment are observed, and the clinicians become comfortable with this usage of antimicrobial agents, then systemic agents will be tried. Eventually, the proper mix of debridement and systemic and locally delivered agents will be developed, and these protocols will become part of the standard of care. This will happen because it will be in the patient's interest for periodontal disease to be prevented and treated, so that the onset of heart disease and other systemic medical conditions can be possibly prevented and/or delayed.

\section{(B) THE MEdical CONNECTION}

In the late 20th century, the paradigm on the etiology of heart disease is changing to suggest a chronic infection hypothesis (Valtonen, 1991), which would include dental infections (Syriänen, 1990; Mattilla et al., 1998). At least 10 studies, after the investigators adjusted for many known risk factors for heart disease, have shown a statistically significant association between various forms of cardiovascular disease and dental disease, especially periodontal disease (Beck et al, 1996; Loesche and Lopatin, 1998). Mattilla and colleagues (1995), in a prospective study, found dental disease to be a significant risk factor for the development of a second heart attack which often culminated in death. In a prospective study of a large number of American males, periodontal disease and edentulousness were statistically associated with coronary heart disease, and with death from any cause, after many known risk factors were adjusted for (DeStefano et al., 1993).

Elderly dependent-living US veterans who reported seeing their dentist at least once a year were almost five times less likely to have suffered a cerebral vascular accident, when compared with elderly veterans who did not see their dentist (Loesche et al., 1998b). Elderly veterans who were dentate and whose plaques were BANA-positive, suggesting the presence of the anaerobic species associated with periodontal disease, were twice as likely to have a diagnosis of coronary heart disease than were elderly dentate veterans whose plaques were BANA-negative (Loesche et al., 1998a).

These results suggest that periodontal disease can be considered a risk factor for cardiovascular diseases. If this is so, then it is a modifiable risk factor, and one that will become a primary target for interceptive and preventive strategies. The management of periodontal disease by means of a treatment strategy based on the Specific Plaque Hypothesis is easier and less expensive to implement than one based on debridement/surgical intervention, as espoused by the Non-specific Plaque Hypothesis.

\section{Acknowledgments}

Studies described in this review have been supported by grants from the National Institute of Dental and Craniofacial Research, DE 06030 and DE-09142. James Giordano, Carol Gerlach. Natalie Grossman, and Christopher Kazor contributed to its preparation.

\section{REFERENCES}

Addy M, Hassan H, Moran J, Wade W, Newcombe R (1988). Use of antimicrobial containing acrylic strips in the treatment of chronic periodontal disease. A three month follow-up study. J Periodontol 59:557-564.

Ainamo J, Lie T, Ellingsen BH, Hansen BF, Johansson LA, Karring T, et al. (1992). Clinical responses to subgingival application of a metronidazole $25 \%$ gel compared to the effect of subgingival scaling in adult periodontitis. J Clin Periodontol 19:723-729.

Aitken S, Birek P, Kulkarni GV, Lee WL, McCulloch CA 
(1992). Serial doxycycline and metronidazole in prevention of recurrent periodontitis in high-risk patients. I Periodontol 63:87-92.

Al-Joburi W, Chin-Ouee T, Lautar C, Iugovaz I, Bourgouin 1. Delorme F, et al. (1989). Effects of adjunctive treatment of periodontitis with tetracycline and spiramycin. I Periodontol 60:533-539.

Ames BN (1986). Food constituents as a source of mutagens, carcinogens and anticarcinogens. Prog Clin Biol Res 206:3-32.

Ames BN, Magaw R, Gold LS (1987). Ranking possible carcinogenic hazards. Science 236:271-280.

Andriole VT (1998). Quinolones. In: Infectious diseases. 2nd ed. Gorbach S, Bartlett J. Blacklow N, editors. Philadelphia: W.B. Saunders Co., pp. 275-289.

Anonymous (1989). In: Newsletter. Vol. 24. Chicago, iL: American Academy of Periodontology, p. 4.

Anonymous (1996a). Systemic antibiotics in periodontics. I Periodontol 67:831-838.

Anonymous (1996b). Consensus report. Non-surgical pocket therapy: mechanical, pharmacotherapeutics, and dental occlusion. Ann Periodontol 1:581-588.

Ashimoto A, Chen C, Bakker I, Slots I (1996). Polymerase chain reaction detection of 8 putative periodontal pathogens in subgingival plaque of gingivitis and advanced periodontal lesions. Oral Microbiol Immunol 11:266-273.

Asikainen S, Jousimies-Somer H, Kanervo A, Saxén L (1990). The immediate efficacy of adjunctive doxycycline in treatment of localized juvenile periodontitis. Arch Oral Biol 35(Suppl):231S-234S.

Barnett ML (1985). Inhibition of oral contraceptive effectiveness by concurrent antibiotic administration. A review. I Periodontol 56: 18-20.

Beck I, Garcia R, Heiss G, Vokonas PS, Offenbacher S (1996). Periodontal disease and cardiovascular disease. I Periodontol 67:1123-1137.

Bollen CM. Vandekerckhove BN, Papaioannou W, Van Eldere 1. Quirynen M (1996). Full- versus partialmouth disinfection in the treatment of periodontal infections. A pilot study: long-term microbiological observations. I Clin Periodontol 23:960-970.

Bollen CM. Mongardini C, Papaioannou W, van Steenberghe D, Quirynen M (1998). The effect of a one-stage full-mouth disinfection on different intraoral niches. Clinical and microbiological observations I Clin Periodontol 25:56-66.

Britt MR, Pohlod DI (1986). Serum and crevicular fluid concentrations after a single oral dose of metronidazole. J Periodontol 57:104-107.

Burtin P, Taddio A, Ariburnu O, Einarson TR, Koren G (1995). Safety of metronidazole in pregnancy: a metaanalysis. Am J Obstet Gynecol 172:525-529.

Calia FM, Oldach DW (1998). Macrolide antibiotics. In:
Infectious diseases. 2nd ed. Gorbach S, Bartlett I, Blacklow N, editors. Philadelphia: W.B. Saunders Co., pp. 242-259.

Chalmers TC, Celano P, Sacks HS, Smith H Ir (1983). Bias in treatment assignment in controlled clinical trials. New Engl J Med 309: 1358-1361.

Cheng S-L، Siboo R, Quee TC, Johnson IL, Mayberry WR, Chan ECS (1985). Comparative study of six random oral spirochete isolates. J Periodont Res 20:602-612.

Chin-Quee T, Chan EC, Clark C, Lauter-Lemay C, Bergeron MJ, Bourgoin J, et al. (1987). The role of adjunctive Rodogyl therapy in the treatment of advanced periodontal disease. A longitudinal clinical and microbiologic study. J Periodontol 58:594-601.

Christersson LA, Zambon II (1993). Suppression of subgingival Actinobacillus actinomycetemcomitans in localized juvenile periodontitis by systemic tetracycline. I Clin Periodontol 20:395-401.

Christersson LA, Fransson CL, Dunford RG, Zambon If (1992). Subgingival distribution of periodontal pathogenic microorganisms in adult periodontitis. I Periodontol 63:418-425.

Clark DC, Shenker S, Stulginski P, Schwartz S (1983). Effectiveness of routine periodontal treatment with and without adjunctive metronidazole therapy in a sample of mentally retarded adolescents. I Periodontol 54:658-665.

Cockburn J, Gibberd RW, Reid AL, Sanson-Fisher RW (1987). Determinants of non-compliance with shortterm antibiotic regimens. Br Med I 295:814-818.

DeStefano F, Anda RF, Kahn HS, Williamson DF, Russell CM (1993). Dental disease and risk of coronary heart disease and mortality. Br Med I 306:688-691.

Drisko CL, Cobb CM, Killoy WI, Michalowicz BS, Pihlstrom BL, Lowenguth RA, et al. (1995). Evaluation of periodontal treatments using controlled-release tetracycline fibers: clinical response. I Periodontol 66:692-699.

Duckworth R, Waterhouse JP, Britton DE, Nuki K, Sheiham A. Winter $R$, et al. (1966). Acute ulcerative gingivitis. A double-blind controlled clinical trial of metronidazole. Br Dent J 120:599-602.

Dzink UL, Socransky SS, Haffajee AD (1988). The predominant cultivable microbiota of active and inactive lesions of destructive periodontal diseases. I Clin Periodontol 15:316-323.

Eisen SA, Miller DK, Woodward RS, Spitznagel E, Przybeck TR (1990). The effect of prescribed daily dose frequency on patient medication compliance. Arch Intern Med 150:1881-1884.

Elter IR, Lawrence HP, Offenbacher S, Beck ID (1997). Meta-analysis of the effect of systemic metronidazole as an adjunct to scaling and root planing for adult periodontitis. I Periodont Res 32:487-496. 
Fiehn NE, Westergaard I (1990). Doxycycline-resistant bacteria in periodontally diseased individuals after systemic doxycycline therapy and in healthy individuals. Oral Microbiol Immunol 5:219-222.

Fitzgerald RJ (1968). Dental caries in gnotobiotic animals. Caries Res 2:139 146.

Flemmig TF, Weinacht S, Rudiger S, Rumetsch $\mathrm{M}$, Jung $\mathrm{A}$, Klaiber B (1996). Adjunctive controlled topical application of tetracycline $\mathrm{HCl}$ in the treatment of localized persistent or recurrent periodontitis. Effects on clinical parameters and elastase-alphal-proteinase inhibitor in gingival crevicular fluid. I Clin Periodontol 23:914-921.

Freedman LS (1990). The effect of partial non-compliance on the power of a clinical trial. Controlled Clin Trials 11:157-168.

Garcia-Rodriguez IA, Garcia-Sanchez JE, TrujillanoMartin T, Garcia-Sanchez E, Garcia-Garcia MI, Fresnadillo-Martinez MJ (1995), In vitro activity of BAY y 3118 and nine other antimicrobial agents against anaerobic bacteria. J Chemother 7:189-196.

Genco RJ (1991). Using antimicrobial agents to manage periodontal diseases. I Am Dent Assoc 122:30-38.

Goene RJ, Winkel EG, Abbas F, Rodenburg IP, van Winkelhoff AI, de Graaff I (1990). Microbiology in diagnosis and treatment of severe periodontitis. A report of four cases. I Periodontol 61:61 64.

Goodson JM (1994). Antimicrobial strategies for treatment of periodontal diseases. Periodontol 2000 5:142168.

Goodson IM, Tanner A, McArdle S, Dix K, Watanabe SM (1991). Multicenter evaluation of tetracycline fiber therapy. III. Microbiological response. I Periodont Res 26:440-45I.

Gordon JM, Walker CB (1993). Current status of systemic antibiotic usage in destructive periodontal disease. I Periodontol 64:760-771.

Gordon J, Walker C, Hovliaras C, Socransky SS (1990). Efficacy of clindamycin hydrochloride in refractory periodontitis: 24-month results. J Periodontol 61:686-691.

Graca MA, Watts TL, Wilson RF, Palmer RM (1997). A randomized controlled trial of a $2 \%$ minocycline gel as an adjunct to non-surgical periodontal treatment, using a design with multiple matching criteria. I Clin Periodontol 24:249-253.

Greenberg RN (1984). Overview of patient compliance with medication. Clin Ther 6:592-599.

Greenstein G, Poulson A (1998). The role of local drug delivery in the management of periodontal disease: a comprehensive review. I Periodontol 69:507-520.

Grossi SG, Zambon JJ, Ho AW, Koch G, Dunford RG, Machtei EE, et al. (1994). Assessment of risk for periodontal disease. 1. Risk indicators for attachment loss. J Periodontol 65:260-267.
Grossi SG, Genco RJ, Machtei EE, Ho AW, Koch G, Dunford R, et al. (1995). Assessment of risk for periodontal disease. Il. Risk indicators for alveolar bone loss. I Periodontol 66:23-29.

Gunsolley IC, Califano IV, Koertge TE, Burmeister IA, Cooper LC, Schenkein HA (1995). Longitudinal assessment of early onset periodontitis. J Periodontol 66:321-328.

Gupta S, Leatham EW, Carrington D, Mendall MA, Kaski IC, Camon AJ (1997). Elevated Chlamydia pneumoniae antibodies, cardiovascular events and azithromycin in male survivors of myocardial infarction. Circulation 96:404-407.

Gusberti FA, Syed SA, Lang NP (1988). Combined antibiotic (metronidazole) and mechanical treatment effects on the subgingival bacterial flora of sites with recurrent periodontal disease. I Clin Periodontol 15:353359.

Haffajee AD, Socransky SS (1994). Microbial etiological agents of destructive periodontal diseases. Periodontol 2000 5:78-111.

Haffajee AD, Dibart S, Kent RL Jr, Socransky SS (1995). Factors associated with different responses to periodontal therapy. I Clin Periodontol 22:628-636.

Haffajee AD, Cugini MA, Tanner A, Pollack RP, Smith C, Kent RL Jr, et al. (1998). Subgingival microbiota in healthy, well-maintained elder and periodontitis subjects. J Clin Periodontol 25:346-353.

Hallström A (1992). Antiarrhythmic drugs: before and after the CAST. WA Public Health 10:48-50.

Hay JW, Yu W (1999). Drug patents and prices: can we achieve better outcomes? In: Measuring the prices of medical treatments. Triplett J, Helms R, editors. Washington, DC: Brookings Institution Press (in press).

Hayes C, Antczak-Bouckoms A, Burdick E (1992). Quality assessment and meta-analysis of systemic tetracycline use in chronic adult periodontitis. I Clin Periodontol 19:164-168.

Helovuo H, Hakkarainen K, Paunio K (1993). Changes in the prevalence of subgingival enteric rods, staphylococci and yeasts after treatment with penicillin and erythromycin. Oral Microbiol Immunol 8:75-79.

Hirshfeld L, Wassermann B (1978). A long-term survey of tooth loss in 600 treated periodontal patients. I Periodontol 49:225-237.

Hujoel PP, DeRouen TA (1995). A survey of endpoint characteristics in periodontal clinical trials published 1988-1992, and implications for future studies. J Clin Periodontol 22:397-407.

Hujoel PP, Leroux BG, DeRouen TA, Powell LV, Kiyak HA (1997). Evaluating the validity of probing attachment loss as a surrogate for tooth mortality in a clinical trial on the elderly. J Dent Res 76:858-866. 
Jones AA, Kornman KS, Newbold DA, Manwell MA (1994). Clinical and microbiological effects of controlled-release locally delivered minocycline in periodontitis. J Periodontol 65:1058-1066.

Ioyston-Bechal S, Smales FC, Duckworth R (1984). Effect of metronidazole on chronic periodontal disease in subjects using a topically applied chlorhexidine gel. I Clin Periodontol 11:53-62.

Kaldahl WB, Kalkwarf PI, Patil KD (1993). A review of longitudinal studies that compared periodontal therapies. I Periodontol 64:243-253

Kamma II, Nakou M, Manti FA (1994). Microbiota of rapidly progressive periodontitis lesions in association with clinical parameters. I Periodontol 65:1073. 1078

Keyes PH (1968). Research in dental caries. I Am Dent Assoc 76:1357-1373.

Keyes PH, Wright WE, Howard S (1978). The use of the phase contrast microscopy and chemotherapy in the diagnosis and treatment of periodontal lesions-initial report. Quintessence Int Rep 15:90-92.

Kulkarni GV, Lee WK, Aitken S, Birek P, McCulloch CA (1991). A randomized, placebo-controlled trial of doxycycline: effect on the microflora of recurrent periodontitis lesions in high risk patients. I Periodontol 62:197-202.

Lacroix IM. Walker CB (1995). Detection and incidence of the tetracycline resistance determinant tet $(M)$ in the microflora associated with adult periodontitis. I Periodontol 66:102-108.

Larsen T (1991). Occurrence of doxycycline resistant bacteria in the oral cavity after local administration of doxycycline in patients with periodontal disease. Scand J Infect Dis 23:89-95.

Larsen T, Fiehn NE (1997). Development of resistance to metronidazole and minocycline in vitro. J Clin Periodontol 24:254-259.

Legg IA, Wilson M (1990). The prevalence of beta-lactamase producing bacteria in subgingival plaque and their sensitivity to Augmentin. Br I Oral Maxillofac Surg 28:180-184

Levy D, Csima A, Birek P, Ellen RP, McCulloch CA (1993). Impact of microbiological consultation on clinical decision making: a case-control study of clinical management of recurrent periodontitis. I Periodontol 64:1029-1039.

Lindhe J (1982). Treatment of localized juvenile periodontitis. In: Host-parasite interactions in periodontal disease. Genco RI, Mergenhagen SE, editors. Washington, DC: ASM Publications, pp. 382-394.

Lindhe 1, Liljenberg B (1984). Treatment of localized juvenile periodontitis. Results after 5 years. I Clin Periodontol 11 399-410

Lindhe I, Liljenberg B, Listgarten MA (1980). Some microbiological and histopathological features of periodontal disease in man. I Periodontol 51:264-269.

Lindhe I, Liljenberg B, Adielson B, Borjesson I (1983). Use of metronidazole as a probe in the study of human periodontal disease. I Clin Periodontol 10:100112.

Listgarten MA (1992). Monitoring the periodontal microbiota as an adjunct to periodontal therapy: rationale, interpretation of test results and application to patient management. Alpha Omegan 85:49-53.

Listgarten MA, Helldén L (1978). Relative distribution of bacteria at clinically healthy and periodontally diseased sites in humans. J Clin Periodontol 5:115-121.

Listgarten MA, Lai CH, Young V (1993). Microbial composition and pattern of antibiotic resistance in subgingival microbial samples from patients with refractory periodontitis. I Periodontol 64:155-161

Loesche WJ (1976). Chemotherapy of dental plaque infections. Oral Sci Rev 9:65-107.

Loesche WJ (1993a). Dental caries: a treatable infection. Grand Haven, MI: Automated Diagnostic Documentation Inc., pp. 1-550.

Loesche WJ (1993b). Bacterial mediators in periodontal disease. Anaerobic bacteria and anaerobic infections. Clin Infect Dis 16(Suppl 4):S203-S210.

Loesche W] (1994). Periodontal disease as a risk factor for heart disease. Compend Cont Educ Dent 15:976-991.

Loesche WI, Giordano IR (1994). Metronidazole in periodontitis V: debridement should precede medication. Compend Cont Educ Dent 15:1198-1218.

Loesche WI, Giordano IR (1997). Treatment paradigms in periodontal disease. Compend Cont Educ Dent 18:221232.

Loesche WJ, Laughon B (1982). Role of spirochetes in periodontal disease. In: Host-parasite interactions in periodontal disease. Genco RJ, Mergenhagen SE, editors. Washington, DC: ASM Publications, pp. 62-80.

Loesche WI, Lopatin DE (1998). Interactions between periodontal disease, medical diseases and immunity in the older individual. Periodontol 2000 16:80-105.

Loesche WI, Nafe D (1973). Reduction of supragingival plaque accumulation in institutionalized Down's syndrome patients by periodic treatment with topical kanamycin. Arch Oral Biol 18:1131-1143.

Loesche WJ, Syed SA, Morrison EC, Kerry GA, Higgins T, Stoll J (1984). Metronidazole in periodontitis. I. Clinical and bacteriological results after 15 to 30 weeks. J Periodontol 55:325-335.

Loesche WI, Syed SA, Schmidt E, Morrison EC (1985). Bacterial profiles of subgingival plaques in periodontitis. J Periodontol 56:447-456.

Loesche W], Bretz WA, Kerschensteiner D, Stoll IA, Socransky SS, Hujoel PP, et al. (1990). Development of a diagnostic test for anaerobic periodontal infections 
based on plaque hydrolysis of benzoyl-DL-argininenaphthylamide. I Clin Microbiol 28:1551-1559.

Loesche WI, Schmidt E, Smith BA, Morrison EC, Caffesse $R$, Hujoel PP (1991). Effects of metronidazole on periodontal treatment needs. J Periodontol 62:247-257.

Loesche WI, Giordano IR, Hujoel P, Schwarcz I, Smith BA (1992a). Metronidazole in periodontitis: reduced need for surgery. I Clin Periodontol 19:103-112.

Loesche WI, Lopatin DE, Stoll I, van Poperin N, Hujoel PP (1992b). Comparison of various detection methods for periodontopathic bacteria: can culture be considered the primary reference standard? I Clin Microbiol 30:418-426.

Loesche WI, Lopatin DE, Giordano I, Alcoforado G, Hujoel P (1992C). Comparison of the benzoyl-DL-arginine-naphthylamide (BANA) test, DNA probes, and immunological reagents for ability to detect anaerobic periodontal infections due to Porphyromonas gingivalis, Treponema denticola, and Bacteroides forsythus. I Clin Microbiol 30:427-433.

Loesche WJ, Grossman N, Giordano J (1993). Metronidazole in periodontitis (IV). The effect of patient compliance on treatment parameters. I Clin Periodontol 20:96-104

Loesche WJ, Giordano J, Soehren S, Hutchinson R, Rau CF, Walsh L, et al. (1996). Nonsurgical treatment of patients with periodontal disease. Oral Surg Oral Med Oral Pathol Oral Radiol Endod 81:533-543.

Loesche WJ, Kazor CE, Taylor GW (1997). The optimization of the BANA test as a screening instrument for gingivitis among subjects seeking treatment. I Clin Periodontol 24:718-726.

Loesche WI, Schork A, Terpenning MS, Chen Y-M, Dominguez L, Grossman N (1998a). Assessing the relationship between dental disease and coronary heart disease in elderly US veterans. I Am Dent Assoc 129:301-311.

Loesche WI, Schork MA, Terpenning MS, Chen Y-M, Kerr $C$, Dominguez L (1998b). The relationship between dental disease and cerebral vascular accident in elderly United States veterans. Ann Periodontol 3:161174

Lopez N, Gamonal IA (1998). Effects of metronidazole plus amoxicillin in progressive untreated adult periodontitis: report of a single 1 -week course after 2 and 4 months. I Periodontol 69:1291 1298.

Lowenguth RA, Chin I, Caton IG, Cobb CM, Drisko CL, Killoy WJ (1995). Evaluation of periodontal treatments using controlled-release tetracycline fibers: microbiological response. I Periodontol 66:700-707.

Lundstrom A, Johansson LA, Hamp SE (1984). Effect of combined systemic antimicrobial therapy and mechanical plaque control in patients with recurrent periodontal disease. J Clin Periodontol 11:321-330.
MacDonald JB, Socransky SS, Gibbons RI (1962). On the pathogenesis of mixed anaerobic infections of mucous membranes. Ann R Coll Surg Engl 31:361-378.

Magnusson 1, Low SB, MCArthur WP, Marks RG, Walker CB, Maruniak I, et al. (1994). Treatment of subjects with refractory periodontal disease |published erratum appears in I Clin Periodontol 22:183, 19951. I Clin Periodontol 21:628-637.

Mahmood MM, Dolby AE (1987). The value of systemically administered metronidazole in the modified Widman flap procedure. J Periodontol 58:147-152.

Maiden MF, Tanner A, McArdle S, Najpauer K, Goodson IM (1991). Tetracycline fiber therapy monitored by DNA probe and cultural methods. I Periodont Res 26:452-459

Mandel ID (1995). Calculus update: prevalence, pathogenicity and prevention. J Am Dent Assoc 126:573-580.

Mandell RL, Socransky SS (1988). Microbiological and clinical effects of surgery plus doxycycline on juvenile periodontitis. I Periodontol 59:373-379.

Mandell RL, Tripodi LS, Savitt E, Goodson IM, Socransky SS (1986). The effect of treatment on Actinobacillus actinomycetemcomitans in localized juvenile periodontitis. I Periodontol 57:94-99.

Mandell RL, Ebersole JL, Socransky SS (1987). Clinical, microbiological and immunological features of active disease sites in juvenile periodontitis. I Clin Periodontol 14:534-540.

Matthews DC, McCulloch CA (1993). Evaluating patient perceptions as short-term outcomes of periodontal treatment: a comparison of surgical and non-surgical therapy. J Periodontol 64: 1029-1039.

Mattila KJ, Valtonen VV, Nieminen MS, Huttunen IK (1995). Dental infection and the risk of new coronary events: prospective study of patients with documented coronary artery disease. Clin Infect Dis 20:588-592.

Mattila KJ, Valtonen $\mathrm{VV}$, Nieminen MS, Asikaninen S (1998). Role of infection as risk factors for atherosclerosis, myocardial infarction, and stroke. Clin Infect Dis 26:719-734.

Mcculloch CA, Birek P, Overall C, Aitken S, Lee W, Kulkarni G (1990). Randomized controlled trial of doxycycline in prevention of recurrent periodontitis in high-risk patients: antimicrobial activity and collagenase inhibition. I Clin Periodontol 17:616-622.

McFall WT (1982). Tooth loss in 100 treated patients with periodontal disease. A long-term study. I Periodontol 53:539-549.

Meador HL, Lane II, Suddick RP (1985). The long-term effectiveness of periodontal therapy in a clinical practice. I Periodontol 56:253-258.

Mombelli A, Gusberti F, Lang NP (1989). Treatment of recurrent periodontal disease by root planing and Ornidazole. I Clin Periodontol 16:38-45 
Mombelii A Tonetti M, Lehmann B, Lang NP (1996). Topographic distribution of black-pigmenting anaerobes before and after periodontal treatment by local delivery of tetracycline. I Clin Periodontol 23:906-913.

Moore WEC, Moore LVH (1994). The bacteria of periodontal diseases. Periodontol 2000 5:66-77.

Nagasawa M. Smith MC, Barnes IH, Fincham IE (1990) Metaranalysis of correlates of diabetes patients' compliance with prescribed medications. Diabetes Educ 16:192-200

Newman MG, Socransky SS (1977). Predominant cultivable microbiota in periodontitis. I Periodont Res 12:120-127.

Newman MG, Kornman KS, Doherty FM (1994). A 6month multi-center evaluation of adjunctive tetracycline fiber therapy used in conjunction with scaling and root planing in maintenance patients: clinical results. I Periodontol 65:685-691.

Novak MJ. Stamatelakys C, Adair SM (1991). Resolution of early lesions of juvenile periodontitis with tetracycline therapy alone: long-term observations of 4 cases. I Periodontol 62:628-633.

Offenbacher S, Katz VL, Fertik GS, Collins IG, Boyd DL, Maynor GB, et al. (1996). Periodontal infection as a possible risk factor for preterm low birth weight. I Periodontol 67:1103-1113.

Oldach DW, Calia FM (1998). Clindamycin. In: Infectious diseases. 2nd edition. Gorbach S, Bartlett J, Blacklow N, editors. Philadelphia: W.B. Saunders Co., pp. 232242.

Olsvik B, Tenover FC (1993). Tetracycline resistance in periodontal pathogens. Clin Infect Dis 16(Suppl 4):S310-5313

Pack PD, Haber I (1983). The incidence of clinical infection after periodontal surgery. A retrospective study. I Periodontol 54:441-443

Palmer RM, Watts TL, Wilson RF (1996). A double-blind trial of tetracycline in the management of early onset periodontitis. I Clin Periodontol 23.670-674.

Papapanou PN, Baelum V, Luan WM, Madianos PN, Chen $X$. Fejerskov O, et al. (1997). Subgingival microbiota in adult Chinese: prevalence and relation to periodontal disease progression. J Periodontol 68:651-666.

Pavicic Ml, van Winkelhoff A], de Graaff I (1992). In vitro susceptibilities of Actinobacillus actinomycetemcomitans to a number of antimicrobial combinations. Antimicrob Agents Chemother 36:2634-2638

Pihlstrom B (1992). Measurement of attachment level in clinical trial: probing methods. I Periodontol 63:10721077.

Polson AM, Garrett S, Stoller NH, Bandt CL, Hanes PI, Killoy WI, et al. (1997a). Multi-center comparative evaluation of subgingivally delivered sanguinarine and doxycycline in the treatment of periodontitis. I.
Study design, procedures, and management. I Periodontol 68:110-118.

Polson AM, Garrett S, Stoller NH, Bandt CL. Hanes PI, Killoy WJ, et al. (1997b). Multi-center comparative evaluation of subgingivally delivered sanguinarine and doxycycline in the treatment of periodontitis. II. Clinical results. J Periodontol 68:119-126.

Ouirynen M, Bollen CM, Vandekerckhove BN, Dekeyser C. Papaioannou W, Eyssen H (1995). Full-vs. partialmouth disinfection in the treatment of periodontal infections: short-term clinical and microbiological observations. I Dent Res 74:1459-1467.

Radvar M, Pourtaghi N, Kinane DF (1996). Comparison of 3 periodontal local antibiotic therapies in persistent periodontal pockets. I Periodontol 67:860-865.

Rams TE, Keyes PH, Wright WE, Howard SA (1984). Longterm effects of microbiologically modulated periodontal therapy on advanced adult periodontitis. I Am Dent Assoc 111:429-441.

Rams TE, Babalola OO, Slots I (1990). Subgingival occurrence of enteric rods, yeasts and staphylococci after systemic doxycycline therapy. Oral Microbiol Immunol 5:166-168

Rams TE, Feik D, Listgarten MA, Slots I (1992). Peptostreptococcus micros in human periodontitis. Oral Microbiol Immunol 7:1-6.

Renvert S, Dahlén G, Wikström M (1996). Treatment of periodontal disease based on microbiological diagnosis. Relation between microbiological and clinical parameters during 5 years. I Periodontol 67:562-571.

Riviere GR, Smith KS, Carranza N Ir, Tzagaroulaki E, Kay SL, Dock M (1995). Subgingival distribution of Treponema denticola, Treponema socranskii, and pathogenrelated oral spirochetes: prevalence and relationship to periodontal status of sampled sites. I Periodontol 66:829-837.

Roe FIC (1983). Toxicological evaluation of metronidazole with particular reference to carcinogenic, mutagenic and teratogenic potential. Surgery 93:158-166.

Rosebury T (1962). Microorganisms indigenous to man. New York: McGraw-Hill, pp. 1-380

Rustia M, Shubik P (1972). Induction of lung tumors and malignant lymphoma in mice by metronidazole. I Natl Cancer Inst 48:721-727.

Saxén L, Asikainen S (1993). Metronidazole in the treatment of localized juvenile periodontitis. I Clin Periodontol 20:166-171.

Sefton AM, Maskell IP, Beighton D, Whiley A, Shain H, Foyle D, et al. (1996). Azithromycin in the treatment of periodontal disease. Effect on microbial flora. I Clin Periodontol 23:998-1003.

Shinn DLS (1962). Metronidazole in acute ulcerative gingivitis. Lancet 1:1191-1192.

Skapski H, Lehner T (1976). A crevicular washing method 
for investigating immune components of crevicular fluid in man. I Periodont Res 11:19-24.

Slots I (1982). Selective medium for isolation of Actinobacillus actinomycetemcomitans. I Clin Microbiol 15:606-609.

Slots I, Rosling BG (1983). Suppression of the periodontopathic microflora in localized juvenile periodontitis by systemic tetracycline. J Clin Periodontol 10:465-486.

Slots 1, Feik D, Rams TE (1990a). Actinobacillus actinomycetemcomitans and Bacteroides intermedius in human periodontitis: age relationship and mutual association. J Clin Periodontol 17:659-662.

Slots I, Feik D, Rams TE (1990b). Prevalence and antimicrobial susceptibility of Enterobacteriaceae, Pseudomonadaceae and Acinetobacter in human periodontitis. Oral Microbiol Immunol 5:149-154.

Socransky SS, Haffajee AD (1993). Effect of therapy on periodontal infections. I Periodontol 64:754-759.

Socransky SS, Haffajee AD, Cugini MA, Smith CM, Kent RL Jr (1998). Microbial complexes in subgingival plaque. I Clin Periodontol 25:134-144.

Söder PÖ, Frithiof L, Wikner S, Wouters F, Engström P-E, et al. (1990). The effect of systemic metronidazole after non-surgical treatment in moderate and advanced periodontitis in young adults. I Periodontol 61:281-288

Soskolne WA (1997). Subgingival delivery of therapeutic agents in the treatment of periodontal diseases. Crit Rev Oral Biol Med 8:164-174.

Soskolne WA, Heasman PA, Stabholz A, Smart GJ, Palmer J. Flashner M, et al. (1997). Sustained local delivery of chlorhexidine in the treatment of periodontitis: a multi-center study. I Periodontol 68:32-38.

Sterry KA, Langeroudi M, Dolby AE (1985). Metronidazole as an adjunct to periodontal therapy with sub-gingival curettage. Br Dent J 158:176-178.

Stewart RB, Caranasos GI (1989). Medication compliance in the elderly. Med Clin North Am 73:1551-1563.

Stoltze K (1995). Elimination of Elyzol 25\% Dentalgel matrix from periodontal pockets. I Clin Periodontol 22:185-187.

Syriänen J (1990). Vascular diseases and oral infections. J Clin Periodontol 17:497-500.

Tally FP, Goldin BR, Sullivan N, Johnson J, Gorback SL (1978). Antimicrobial activity of metronidazole in anaerobic bacteria. Antimicrob Agents Chemother 13:460465.

Tanner ACR, Haffer C, Bratthall GT, Visconti RA, Socransky SS (1979). A study of the bacteria associated with advancing periodontitis in man. I Clin Periodontol 6:278-307

Timmerman MF, van der Weijden GA, van Steenbergen TJ, Mantel MS, de Graaff J, Van der Velden U (1996). Evaluation of the long-term efficacy and safety of locally-applied minocycline in adult periodontitis patients. I Clin Periodontol 23:707-716

Tonetti MS, Cugini MA, Goodson IM (1990). Zero-order delivery with periodontal placement of tetracyclineloaded ethylene vinyl acetate fibers. I Periodont Res 25:243-249.

Topoll HH, Lange DE, Muller RF (1990). Multiple periodontal abscesses after systemic antibiotic therapy. I Clin Periodontol 17:268-272.

Tseng CC, Huang CC, Tseng WH (1993). Incidence of clinical infection after periodontal surgery: a prospective study. I Formosa Med Assoc 92:152-156.

Umeda $M$, Tominaga $Y$, He $T$, Yano $K$, Watanabe $H$, Ishikawa I (1996). Microbial flora in the acute phase of periodontitis and the effect of local administration of minocycline. I Periodontol 67:422-427.

Valtonen W (1991). Infection as a risk factor for infarction and atherosclerosis. Ann Med 23:539-543.

van Steenberghe D, Bercy P, Kohl I, DeBoever J, Adriaens P, Vanderfaeillie A, et al. (1993). Subgingival minocycline hydrochloride ointment in moderate to severe chronic adult periodontitis: a randomized, doubleblind, vehicle-controlled, multicenter study. J Periodontol 64:637-644.

van Winkelhoff AJ, Rodenburg IP, Goene RJ, Abbas F, Winkel EG, de Graaff J (1989). Metronidazole plus amoxycillin in the treatment of Actinobacillus actinomycetemcomitans associated periodontitis. I Clin Periodontol 16:128-131.

van Winkelhoff AJ, Tijhof CJ, de Graaff J (1992). Microbiological and clinical results of metronidazole plus amoxicillin therapy in Actinobacillus actinomycetemcomitans-associated periodontitis. I Periodontol 63:52-57.

van Winkelhoff AJ, Winkel EG, Barendregt D, DellemijnKippuw N, Stijne A, Van der Velden U (1997). Beta-lactamase producing bacteria in adult periodontitis. I Clin Periodontol 24:538-543.

Vandekerckhove BN, Quirynen $M$, van Steenberghe D (1997). The use of tetracycline-containing controlledrelease fibers in the treatment of refractory periodontitis. I Periodontol 68:353-361

Wade WG, Moran J, Morgan IR, Newcombe R, Addy M (1992). The effects of antimicrobial acrylic strips on the subgingival microflora in chronic periodontitis. I Clin Periodontol 19:127-134.

Walker C, Gordon J (1990). The effect of clindamycin on the microbiota associated with refractory periodontitis. J Periodontol 61:692-698.

Walker CB, Pappas JD, Tyler KZ, Cohen S, Gordon IM (1985). Antibiotic susceptibilities of periodontal bacteria. In vitro susceptibilities to eight antimicrobial agents. J Periodontol 56:67-74.

Walker CB, Gordon JM, Magnusson I, Clark WB (1993). A role for antibiotics in the treatment of refractory periodontitis. J Periodontol 64:772-781. 
Watts T, Palmer R, Floyd P (1986). Metronidazole: a double-blind trial in untreated human periodontal disease. J Clin Periodontol 13:939-943.

Winkel EG, van Winkelhoff AJ, Timmerman MF, Vangsted $T$, Van der Velden U (1997). Effects of metronidazole in patients with "refractory" periodontitis associated with Bacteroides forsythus. I Clin Periodontol 24:573-579.
Winkler JR, Murray PA, Grassi M, Hämmerle C (1989). Diagnosis and management of HIV-associated periodontal lesions. I Am Dent Assoc 120(Suppl):25S-34S.

Zambon II (1985). Actinobacillus actinomycetemcomitans in human periodontal disease. J Clin Periodontol 12:1-20. Zambon If (1997). Rapid diagnosis of periodontal infections: findings in AIDS patients. Immunol Invest 26:55-65. 